Sharif University of Technology
Scientia Iranica
Transactions E: Industrial Engineering
http://scientiairanica.sharif.edu

\title{
Optimal production and ordering strategies with defective items and allowable shortage under two-part trade credit
}

\author{
C.-T. Yang ${ }^{\mathrm{a}}$, C.-H. Huang ${ }^{\mathrm{b}, *}$, and L.-Y. Ouyang ${ }^{\mathrm{b}}$ \\ a. Department of Industrial Management, Chien Hsin University of Science and Technology, Taoyuan City, Taiwan. \\ b. Department of Management Sciences, Tamkang University, New Taipei City, Taiwan.
}

Received 20 December 2016; received in revised form 6 April 2017; accepted 6 June 2018

\section{KEYWORDS}

Inventory;

Supply chain;

Defective items;

Backlogged;

Trade credit.

\begin{abstract}
This study investigated a production-inventory model with defective items under a two-part trade credit, where the agreement of conditionally freight concession is considered in an integrated supply chain. It is assumed here that the retailer conducts the inspection process before selling incoming items. All the defective items are discovered, stored, and sold as a single batch to a secondary market at a decreased price. Furthermore, shortages are allowed and completely backlogged for the retailer. The purpose of this study is to determine the optimal number of shipments per production cycle for the supplier and the optimal length of time when there is no inventory shortage and replenishment cycle for the retailer, such that the total profit function has a maximum value. In theoretical analysis, the existence and uniqueness of the optimal solutions are shown, and an algorithm is developed to find the optimal solutions. Furthermore, numerical examples are presented to demonstrate the solution procedures, and a sensitivity analysis of the optimal solutions regarding all parameters is also carried out.
\end{abstract}

(C) 2019 Sharif University of Technology. All rights reserved.

\section{Introduction}

The traditional Economic Order Quantity (EOQ) model does not investigate payment methods when the retailer receives goods from the supplier, and it is assumed that payment is made immediately upon receiving the consignment. However, in real business transactions, to attract new customers and increase sales or market shares, the supplier typically allows the retailer an extended period for making full payment. This is a common business practice because it benefits both the supplier and the retailer. For example, Emery [1] indicated that the supplier often increases

*. Corresponding author. Fax: 886-2-2623-7384 E-mail address: hch001@mail.tku.edu.tw (C.-H. Huang).

doi: $10.24200 /$ sci. 2018.20032 sales by offering trade credit. Moreover, the retailer can accumulate revenue from sales and earn interest on that revenue during this credit period. Petersen and Rajan [2] further noted that trade credit was the widely used and accepted short-term source of funding. Goyal [3] initially incorporated the issue of trade credit into EOQ model. Aggarwal and Jaggi [4] extended Goyal's model [3] to consider deteriorating items. Chang et al. [5] established an EOQ model for deteriorating items where the supplier provides a delay in payments to the purchaser if the order quantity is greater than or equal to a predetermined quantity, which is known as a conditionally permissible delay in payments. Ouyang et al. [6] presented an inventory model for non-instantaneous deteriorating items with permissible delay in payments. Teng [7] attempted to establish an EOQ model for the retailer, wherein a distinct trade credit was offered to customers 
with different types of credit. Ouyang et al. [8] expanded on the model proposed by Goyal [3] to consider deteriorating items and partially permissible delays in payment associated with order quantity. Yang et al. [9] investigated how the retailer determines the optimal ordering and payment polices when the supplier offers cash discounts or delayed payments depending on the order quantity. Sarker et al. [10] developed an inventory model for different types of time-varying demand, where different discount rates for different delay periods are considered. Sarkar et al. [11] considered a deteriorating inventory model with twolevel trade credits for fixed lifetime products. Recently, Lashgari et al. [12] investigated an inventory control problem for deteriorating items with two-level trade credit linked to order quantity. Related articles include studies by Sana [13], Khanra et al. [14], Sarkar [15], Jaggi et al. [16], Khanra et al. [17], Ray [18], Khanra et al. [19], and their references.

The aforementioned studies have assumed that the items received are of perfect quality. However, in actual production environments, product quality is not consistently perfect because of imperfect manufacturing and poor handling procedures. Retailers frequently receive defective products, which affect practical inventory levels and increase the risk of shortages and frequency of purchases. Certain studies on inventory models have accounted for this complication. Rosenblatt and Lee [20] considered the effect of imperfect production processes on the Economic Production Quantity (EPQ) model. Porteus [21] incorporated the effect of the defective items into the $\mathrm{EPQ}$ model and considered investing capital in production processes to improve product quality. Lee and Rosenblatt [22] considered an economic manufacturing quantity model wherein production cycle length and equipment maintenance intervals were treated as decision variables. Lee and Rosenblatt [23] further incorporated maintenance and recovery costs of the machine into an EPQ model with imperfect production processes. Zhang and Gerchak [24] developed an EOQ model to determine the optimal order quantity and inspection strategy, in which defective products are randomly produced. Groenevelt et al. [25] established an EPQ model by accounting for equipment damage and related maintenance to determine optimal production quantity. Kim and Hong [26] extended the model proposed by Rosenblatt and Lee [20] to determine the optimal length of production run in deteriorating production processes. Wu et al. [27] investigated the effects of quality-guaranteed strategies on the optimal production quantity, wherein the manufacturer offers free repairs for detective products. Tayyab and Sarkar [28] revisited an EPQ model with an imperfect multi-stage production system by considering a random defective rate. Related articles include studies by Khan et al. [29], Sarkar [30], Hsu and Hsu [31], Hsu et al. [32], $\mathrm{Yu}$ and Lin [33], Moussawi-Haidar et al. [34], and their references. Most of these studies have examined how defective products affect optimal production and ordering strategies. However, they have not considered the treatment of defective items.

To ensure quality of goods and maintain a good reputation, companies often make quality inspections frequently and establish disposal processes for defective items prior to sale. Salameh and Jaber [35] considered an EPQ model wherein defective products are discovered during inspection and, then, sold at discounted prices in the secondary markets. Chan et al. [36] incorporated product inspection of all goods into an EPQ model, wherein defective goods are treated by selling them at discounted prices, reworking them, or rejecting them. Chiu [37] developed an EPQ model that considered shortages, and assumed that randomly produced defective products were reworked or discarded. Related studies include those of Chiu [38], Kulkarni [39], Sarker et al. [40], El Saadany and Jaber [41], Sana [42], Sarkar et al. [43-44], Sarkar [45], Ouyang and Chang [46], Tsao et al. [47], Sarkar et al. [48-49], Sarkar and Moon [50], and so on.

When encountering a competitive market and a changing business environment, companies must enhance their operational efficiency, respond to customers' needs rapidly, attempt to reduce inventory costs, and increase profits through the integration of the supply chain system. Therefore, the issues of Supply Chain Management (SCM) about how to integrate suppliers with retailers to establish appropriate production-inventory models and determine the optimal production and ordering strategies that jointly achieve cost minimization or profit maximization have attracted much academic attention. Banerjee [51] developed a joint economic-lot-size model wherein the supplier produces to satisfy orders for a retailer on a lot-for-lot basis. Goyal [52] adjusted Banerjee's model, and noted that when the supplier's setup cost is substantially larger than the retailer's ordering cost, the lot-for-lot method is not optimal. Furthermore, he relaxed the assumption of lit-for-lot policy, surmising that his revised model provided a lower or equal joint total relevant cost. Lu [53] further extended the model proposed by Goyal [52] to consider an integrated inventory model for a single supplier and multiple retailers and relaxed the assumption that shipments could not be arranged before the production batch is completed. Recently, Pal et al. [54] considered a two-echelon competitive supply chain with trade credit policy. Alternative production-inventory models that have investigated various aspects of the coordination of supply chains are as follows: Goyal [55], Yao and Chiou [56], Chung and Wee [57], Chang et al. [58], Lin and Lin [59], Cárdenas-Barrón et al. [60], Lin et al. [61], 
Su [62], Sana [63], Das et al. [64], Ouyang et al. [65], Giri and Sharma [66], Ouyang et al. [67], Sana [68], Sarkar [69], Mahata et al. [70], and their references.

To bring the production-inventory models of the supply chain into concurrence with the actual business environment and industrial demand, this paper examines the optimal production and order polices for an integrated supply chain system including:

1. The retailer's arriving lot contains some defective items that are assessed, stored, and then sold in a single batch to a secondary market at a decreased price;

2. Shortages are allowed for the retailer and completely backlogged;

3. If the order quantity of the retailer is greater than or equal to the specified threshold, the transportation cost is paid by the supplier; otherwise, it is paid by the retailer;

4. The supplier provides a two-part trade credit that allows the retailer to make full payment at the time or to pay at an earlier time with a cash discount.

First, the total profit functions for the supplier and retailer are developed and, then, integrated appropriately to determine the joint total profit function of the supply chain. The purpose of this study is to determine the optimal number of shipments per production cycle for the supplier, the optimal length of time wherein there is no inventory shortage, and the length of replenishment cycle for the retailer so as to maximize the joint total profit function. Furthermore, the existence and uniqueness of the optimal solutions are shown, and an algorithm is developed to find the optimal solutions. Finally, numerical examples are presented to demonstrate the solution procedures, and a sensitivity analysis of the optimal solutions with respect to all parameters is described. Different from the previous literature, the major issues considered in the above-mentioned studies compared with the present paper are summarized in Table 1.

\section{Problem description}

In this model, a single supplier and a single retailer are considered in a supply chain production-inventory system. The operation of this production inventory system is as follows: the retailer orders $Q$ units per order and the supplier produces $n Q$ units per production run and delivers them to the retailer in $n$ shipments, where $n$ is a integer. Each shipment contains certain defective items at a defect rate of $\lambda$, and $100 \%$ inspection is conducted by the retailer before selling them. All defective items will be discovered, stored, and then sold to the secondary market with a lower unit price in a single batch after inspection. Further, to encourage the retailer to order more, the supplier provides the retailer with a conditionally freight concession. That is, when the order quantity of retailer $Q$ is greater than or equal to a certain threshold, $Q_{d}$, then the transportation cost is absorbed by the supplier; otherwise, it is paid by the retailer. On the other hand, to facilitate the transaction and receive payment as soon as possible, the supplier provides the retailer with a two-part trade credit, which allows the retailer to make payments at time $M_{2}$ and, then, provides the retailer with a cash discount and a discount rate $\alpha(0<\alpha<1)$. If the retailer pays earlier at time $M_{1}$, where $0 \leq M_{1}<M_{2}$, the entire process is repeated. To develop this model, the notations and assumptions are used as follows.

$P \quad$ Supplier's production rate;

$D \quad$ Retailer's demand rate;

$K \quad$ Supplier's setup cost per setup;

$A \quad$ Retailer's ordering cost per order;

$F \quad$ Fixed transportation cost per shipment;

$r \quad$ Variable transportation cost per unit;

$h_{v} \quad$ Supplier's holding cost per unit per unit time;

$h_{b_{1}} \quad$ Retailer's holding cost per nondefective item per unit time excluding interest charge;

$h_{b_{2}} \quad$ Retailer's holding cost per defective item per unit time excluding interest charge, where $h_{b_{2}} \leq h_{b_{1}}$;

$\pi \quad$ Retailer's shortage cost per unit per unit time;

c Supplier's production cost per unit;

$v \quad$ Retailer's wholesale price per unit, where $v>c$;

$p \quad$ Retailer's unit selling price of non-defective items, where $p>v$;

$k \quad$ Retailer's unit selling price of defective items in the secondary market, where $0<k<v$;

$\lambda \quad$ Defective rate, where $\lambda \in[0,1)$;

$M_{i} \quad$ Trade credit period offered by the supplier, where $i=1,2$ and $0 \leq M_{1}<M_{2}$;

$I_{v} \quad$ Supplier's capital opportunity cost per dollar per unit time due to offering trade credit to the retailer;

$I_{e} \quad$ Retailer's interest earned per dollar per unit time; 
Table 1. A brief literature review of related references.

\begin{tabular}{|c|c|c|c|c|c|}
\hline Reference & Trade credit & $\begin{array}{l}\text { Individual } \\
\text { /supply chain } \\
\text { perspective }\end{array}$ & $\begin{array}{l}\text { Defective } \\
\text { item }\end{array}$ & Shortage & $\begin{array}{c}\text { Quantity } \\
\text {-dependent } \\
\text { freight }\end{array}$ \\
\hline$[1,2]$ & No & Individual & No & No & No \\
\hline $\begin{array}{l}{[3,4,6,10]} \\
{[14-15,18]}\end{array}$ & Yes & Individual (EOQ) & No & No & No \\
\hline$[5]$ & Conditionally & Individual (EOQ) & No & No & No \\
\hline$[7,8]$ & Partially & Individual (EOQ) & No & No & No \\
\hline$[9]$ & Two-part & Individual (EOQ) & No & No & No \\
\hline [11] & Two-levels & Individual (EPQ) & No & No & No \\
\hline [12] & Two-levels & Individual (EOQ) & No & Completely backlogging & No \\
\hline [13] & Yes & Individual (EPQ) & No & No & No \\
\hline$[16]$ & Two-levels & Individual (EOQ) & No & No & No \\
\hline$[17,19]$ & Yes & Individual (EOQ) & No & Completely backlogging & No \\
\hline $\begin{array}{c}{[20,21-23,25-26]} \\
{[29,35-36,40-45,49]}\end{array}$ & No & Individual (EPQ) & Yes & No & No \\
\hline$[24,28,32,50]$ & No & Individual (EOQ) & Yes & No & No \\
\hline$[27]$ & No & Individual & Yes & No & No \\
\hline$[30]$ & Yes & Individual (EOQ) & Yes & No & No \\
\hline$[31,33-34]$ & No & Individual (EOQ) & Yes & Completely backlogging & No \\
\hline$[37]$ & No & Individual (EPQ) & Yes & Partially backlogging & No \\
\hline [38-39] & No & Individual (EPQ) & Yes & Completely backlogging & No \\
\hline$[46]$ & Yes & Individual (EPQ) & Yes & Completely backlogging & No \\
\hline$[47]$ & Yes & Individual (EPQ) & Yes & No & No \\
\hline$[48,61]$ & Yes & Supply chain & Yes & No & No \\
\hline $\begin{array}{l}{[51-53,55-56]} \\
{[60,63,67-69]}\end{array}$ & No & Supply chain & No & No & No \\
\hline$[54,58,64]$ & Yes & Supply chain & No & No & No \\
\hline$[57]$ & No & Supply chain & No & Completely backlogging & No \\
\hline$[59]$ & No & Supply chain & Yes & No & No \\
\hline$[62,66]$ & Yes & Supply chain & Yes & Completely backlogging & No \\
\hline$[65]$ & Two-part & Supply chain & Yes & No & No \\
\hline$[70]$ & Two-levels & Supply chain & No & No & No \\
\hline Present paper & Two-part & Supply chain & Yes & Completely backlogging & Yes \\
\hline
\end{tabular}

$I_{c} \quad$ Retailer's capital opportunity cost per dollar in stocks per unit time;

$I_{p} \quad$ Supplier's interest earned per dollar per unit time when the retailer pays at early time $M_{1}$;

$\alpha$
Price discount rate offered by the supper when the retailer pays at time $M_{1}$, where $0<\alpha<1$;
$Q_{d} \quad$ Retailer's order quantity threshold at which shipping cost is absorbed by the supplier;

$Q \quad$ Retailer's order quantity;

$B$ Maximum backlogging level during the stock-out period;

$n \quad$ Number of shipment from the supplier to the retailer per production cycle; 

which the stock reaches zero; Retailer's length of the replenishment cycle time.

\section{Assumptions}

1. Similar to the models of Sarkar et al. [48], Sana [63], and Sarkar et al. [71], the production-inventory system considers a single supplier, a single retailer, and single commodity;

2. Shortages are allowed for the retailer and all customers are willing to wait for the next delivery (see, for example $[31,46])$;

3. Replenishment rate of the retailer is infinite, and the lead time is assumed to be negligible (this assumption was used by Sarkar et al. [10], El Saadany [41], Sana [68], Sett et al. [72], and so on);

4. The retailer orders $Q$ units per order and the supplier produces $n Q$ units per production run and delivers them to the retailer in $n$ shipments, where $n$ is an integer;

5. To achieve economies of scale on transportation, the supplier provides the retailer with a freight concession. When the order quantity of retailer $Q$ is greater than or equal to $Q_{d}$, then transportation cost is absorbed by the supplier; otherwise, it is paid by the retailer;

6. An arriving lot contains some defective items with defective rate $\lambda$, and the retailer may perform a $100 \%$ inspection to check the product quality before selling it. Defective items in each batch are discovered, stored and then sold to the secondary market in a single batch at the end of each cycle (see, for example, [73]). Hence, the retailer's holding cost includes two parts: non-defective items and defective items;

7. To attract procurement from the retailer, the supplier provides the retailer with a two-part trade credit. That is, the supplier allows the retailer to make the payment at time $M_{2}$ and provides the retailer with a cash discount and a discount rate $\alpha(0<\alpha<1)$ if the retailer pays earlier at time $M_{1}$, where $0 \leq M_{1}<M_{2}$;

8. During the time when the account has not been settled, the generated sale revenue is deposited in an interest-bearing account at a rate of $I_{e}$. At the end of this period $\left(M_{i}, i=1,2\right)$, the retailer pays the purchasing cost to the supplier and incurs a capital opportunity cost at a rate of $I_{c}$ for the items in stock;

9. When the retailer pays earlier at time $M_{1}$, the supplier may gain an interest earned at a rate of $I_{p}$ during the time interval $M_{1}, M_{2}$;
10. The retailer's inspection process is assumed fast, error-free and non-destructive. That is, the inspection time is ignored.

\section{Model formulation}

Based on the notations and assumptions mentioned above, this section first establishes the total profit functions for the supplier and retailer and, then, makes some appropriate combination of the two to obtain an integrated total profit function.

\subsection{Supplier's total profit function}

The supplier's total profit per production cycle is the gross profit on sale minus the total relevant cost, which consists of the setup cost, transportation cost, inventory holding cost, opportunity cost for offering trade credit, and interest earned during the time interval $\left[M_{1}, M_{2}\right]$ if the retailer make the payment at the time $M_{1}$. These components are evaluated as follows:

1. Gross profit on sale. When the retailer pays at time $M_{i}(i=1,2)$, the unit wholesale price is $\left(1-\delta_{i} \alpha\right) v$, where $\delta_{1}=1, \delta_{2}=0$. Because the supplier's unit production cost is $c$, the supplier's gross profit on sale per production cycle is $\left.n\left(1-\delta_{i} \alpha\right) v-c\right] Q$;

2. Setup cost. The supplier's setup cost in a production cycle is $K$;

3. Transportation cost. The transportation cost includes fixed and variable costs (see, for example, [74]). Further, if the retailer's order quantity is larger than or equal to specified threshold $Q_{d}$, then the transportation cost is absorbed by the supplier; otherwise, the transportation cost is paid by the retailer. Hence, the transportation cost is given by $I_{\left[Q_{d}, \infty\right)}(Q)(F+r Q)$, where $I_{\left[Q_{d}, \infty\right)}(Q)$ is an indicator function and defined as follows:

$$
I_{\left[Q_{d}, \infty\right)}(Q)= \begin{cases}1 & \text { if } Q \geq Q_{d} \\ 0 & \text { if } Q<Q_{d}\end{cases}
$$

Therefore, the supplier's transportation cost per production cycle is $n I_{[Q d, \infty)}(Q)(F+r Q)$;

4. Holding cost. At the beginning, when a quantity of products are produced, the supplier will deliver them to the retailer immediately. After the first shipment, the supplier will schedule successive deliveries in every $(1-\lambda) Q / D$ unit of time until the inventory level falls to zero. Consequently, the supplier's total inventory quantity per production cycle is equal to its cumulative inventory minus the retailer's cumulative inventory (see Figure 1) and is given by: 


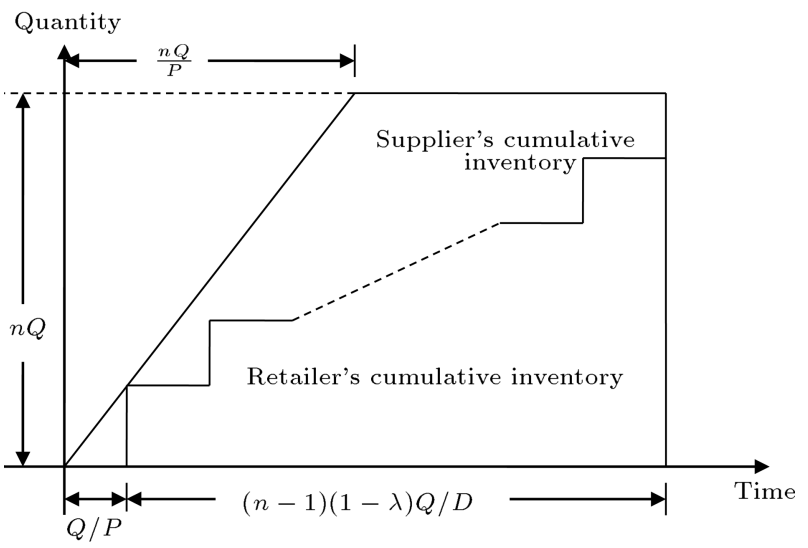

Figure 1. The supplier's inventory system.

$$
\begin{aligned}
n Q\left[\frac{Q}{p}\right. & \left.+\frac{(n-1)(1-\gamma) Q}{D}\right]-\frac{n Q}{2} \cdot \frac{n Q}{P} \\
& -[1+2+\ldots(n-1)] Q \cdot \frac{(1-\lambda) Q}{D} \\
& =n Q^{2}\left[\frac{1}{P}+\frac{(n-1)(1-\lambda)}{2 D}-\frac{n}{2 P}\right] .
\end{aligned}
$$

With unit holding cost per unit time, $h_{v}$, the supplier's total holding cost per production cycle is as follows:

$$
h_{v} n Q^{2}\left[\frac{1}{P}+\frac{(n-1)(1-\lambda)}{2 D}-\frac{n}{2 P}\right] \text {. }
$$

Note that a similar derivation in the supplier's total holding cost can be found in the study of Sarkar and Majumder [75];

5. Opportunity cost. Because the supplier provides the retailer with a two-part trade credit, which implies that the retailer is allowed to make the payment at time $M_{i}(i=1,2)$ after receiving the order quantity, there is an opportunity cost arising for the supplier due to the trade credit. The supplier's opportunity cost per production cycle is $n I_{v}\left(1-\sigma_{i} \alpha\right) v Q M_{i}$, where $i=1,2$ and $\delta_{1}=1, \delta_{2}=0$;

6. Interest earned from sale revenue. If the retailer pays earlier at time $M_{1}$, then the supplier may use sale revenue $(1-\alpha) v Q$ to gain an interest earned at a rate of $I_{P}$ during the time interval $\left[M_{1}, M_{2}\right]$. Hence, when the retailer makes payments at time $M_{1}$, the supplier's interest earned per replenishment cycle during the time interval $\left[M_{1}, M_{2}\right]$ is $I_{p}(1-$ a) $v Q\left(M_{2}-M_{1}\right)$. Otherwise, if the retailer pays at time $M_{2}$, then the supplier's interest earned during $\left[M_{1}, M_{2}\right]$ is zero. Therefore, the supplier's interest earned per production cycle is as follows:

$$
n \delta_{i} I_{p}(1-\alpha) v Q\left(M_{2}-M_{1}\right),
$$

where $i=1,2$ and $\delta_{1}=1, \delta_{2}=0$. Consequently, the supplier's total profit per unit time (denoted by $\left.T P V_{i}(n)\right)$ is a function of $n$ and can be expressed as follows:

$$
\begin{aligned}
& T P V_{i}(n)=\frac{1}{n T}\{\text { gross profit - setup cost } \\
& \text { - transportation cost - holding cost } \\
& \text { - opportunity cost }+ \text { interest earned }\} \\
& =\frac{1}{T}\left\{\left[\left(1-\delta_{i} \alpha\right) v-c\right] Q-\frac{K}{n}\right. \\
& -I_{\left[Q_{d}, \infty\right)}(Q)(F+r Q)-h_{v} Q^{2} \\
& {\left[\frac{1}{P}+\frac{(n-1)(1-\lambda)}{2 D}-\frac{n}{2 P}\right]} \\
& -I_{v}\left(1-\delta_{i} \alpha\right) v Q M_{i} \\
& \left.+\delta_{i} I_{p}(1-\alpha) v Q\left(M_{2}-M_{1}\right)\right\} \\
& =\frac{\left[\left(1-\delta_{i} \alpha\right) v-c\right] D}{1-\lambda}-\frac{K}{n T}-I_{\left[Q_{d}, \infty\right)} \\
& (Q)\left(\frac{F}{T}+\frac{r D}{1-\lambda}\right)-\frac{h_{v} D^{2} T}{(1-\lambda)^{2}} \\
& {\left[\frac{1}{P}+\frac{(n-1)(1-\lambda)}{2 D}-\frac{n}{2 P}\right]} \\
& -\frac{I_{v}\left(1-\delta_{i} \alpha\right) v D M_{i}}{1-\lambda} \\
& +\frac{\delta_{i} I_{p}(1-\alpha) v D\left(M_{2}-M_{1}\right)}{1-\lambda},
\end{aligned}
$$

where $i=1,2$ and $\delta_{1}=1, \delta_{2}=0$.

\subsection{Retailer's total profit function}

With regard to the retailer, its total profit per production cycle is the gross profit on sale minus the total relevant cost, which consists of the ordering cost, transportation cost, inventory holding cost, shortage cost, opportunity cost, and interest earned. These components are evaluated as follows:

1. Gross profit. The retailer's sale revenue includes non-detective and detective items which are $p(1-$ $\lambda) Q=p D T$ and $k \lambda Q=k \lambda D T /(1-\lambda)$, respectively. In addition, the retailer's total purchasing cost is $\left(1-\delta_{i} \alpha\right) v Q=\left(1-\delta_{i} \alpha\right) v D T /(1-\lambda), i=1,2$, and $\delta_{1}=1, \delta_{2}=0$. Hence, the retailer's gross profit per replenishment cycle is:

$$
p D T+\frac{k \lambda D T}{1-\lambda}-\frac{\left(1-\delta_{i} \alpha\right) v D T}{1-\lambda},
$$


where $i=1,2$ and $\delta_{1}=1, \delta_{2}=0$.

2. Ordering cost. The retailer's ordering cost per replenishment cycle is $A$.

3. Transportation cost. The retailer's transportation cost per replenishment cycle is $\left[1-I_{\left[Q_{d}, \infty\right)}(Q)\right](F+$ $r Q)$.

4. Holding cost. Because the retailer's maximum inventory level for non-detective items is $(1-\lambda) Q-$ $B$ with the length of cycle time $t$, the holding cost for non-detective items is $h_{b_{1}} \frac{[(1-\lambda) Q-B] t}{2}$. On the other hand, after speedy inspection while receiving the order, there are $\lambda Q$ detective items per replenishment cycle. Hence, the holding cost is $h_{b_{2}} \lambda Q T$. In summary, the retailer's total holding cost per replenishment cycle is:

$h_{b_{1}} \frac{[(1-\lambda) Q-B] t}{2}+h_{b_{2}} \lambda Q T=\frac{h_{b_{1}} D t^{2}}{2}+\frac{h_{b_{2}} \lambda D T^{2}}{1-\lambda}$.

5. Shortage cost. Since shortage is allowed and completely backlogged during the stock-out period, the retailer's shortage cost per replenishment cycle is:

$$
\pi \frac{B(T-t)}{2}=\frac{\pi D(T-t)^{2}}{2} .
$$

6. Interest earned and interest charged. Based on the values of $M_{i}(i=1,2), t$ and $T$, three cases, including (i) $M_{i} \leq t \leq T$, (ii) $t \leq M_{i} \leq T$, and (iii) $t \leq T \leq M_{i}$ may occur.

Case 1: $M_{i} \leq t \leq T(i=1,2)$. In this case, as shown in Figure 2, for given $M_{i}(i=1,2)$, the retailer's interest earned at a rate of $I_{p}$ per cycle is $\frac{I_{e} p D M_{i}^{2}}{2}+$ $I_{e} p B M_{i}=\frac{I_{e} p D M_{i}^{2}}{2}+I_{e} p D(T-t) M_{i}$, where $I_{e} p B M_{i}$ is the interest earned due to the revenue from backlogged demand.

After payment time, $M_{i}$, the retailer pays off the purchasing cost and, then, incurs a capital opportunity cost at a rate of $I_{c}$ for the items in stock including non-detective and detective parts. The opportunity

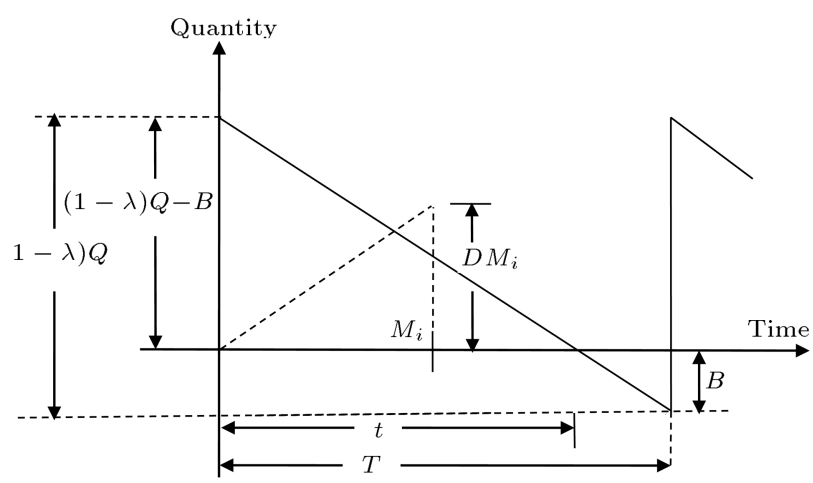

Figure 2. The retailer's inventory system when $M_{i} \leq t \leq T(i=1,2)$.

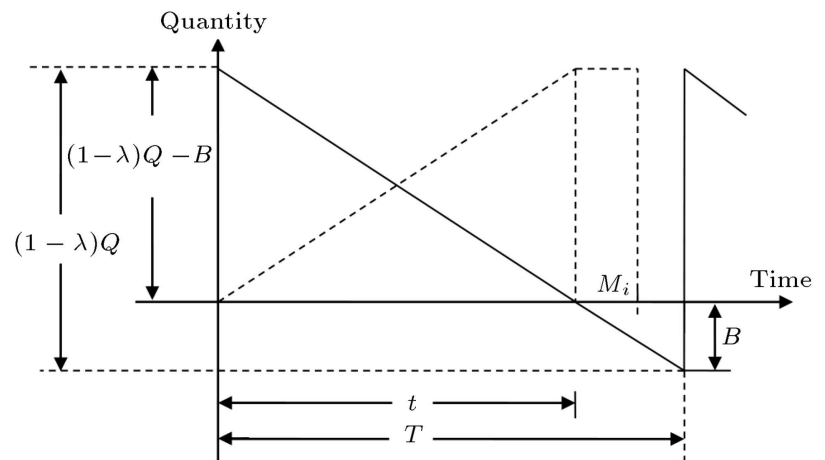

Figure 3. The retailer's inventory system when $t \leq M_{i} \leq T(i=1,2)$.

cost for non-detective items per replenishment cycle is $I_{c}\left(1-\delta_{i} \alpha\right) v D\left(t-M_{i}\right)^{2} / 2$. As for detective items, the opportunity cost per replenishment cycle is $I_{c}(1-$ $\left.\delta_{i} \alpha\right) v \lambda Q\left(T-M_{i}\right)=I_{c}\left(1-\delta_{i} \alpha\right) v \lambda D T\left(T-M_{i}\right) /(1-$ $\lambda)$. Therefore, the retailer's opportunity cost per replenishment cycle is:

$\frac{I_{c}\left(1-\delta_{i} \alpha\right) v D\left(t-M_{i}\right)^{2}}{2}+\frac{I_{c}\left(1-\delta_{i} \alpha\right) v \lambda D T\left(T-M_{i}\right)}{1-\lambda}$,

where $i=1,2$ and $\delta_{1}=1, \delta_{2}=0$.

Case 2: $\quad t \leq M_{i} \leq T(i=1,2)$. In this case, as shown in Figure 3, the retailer's interest earned when paying at time $M_{i}(i=1,2)$ per replenishment cycle is:

$$
\begin{aligned}
& \frac{I_{e} p[(1-\lambda) Q-B] t}{2}+I_{e} p[(1-\lambda) Q-B]\left(M_{i}-t\right) \\
& \quad+I_{e} p B M_{i}=I_{e} p D t\left(M_{i}-\frac{t}{2}\right)+I_{e} p D(T-t) M_{i}
\end{aligned}
$$

where $I_{e} p B M_{i}$ is the interest earned due to the revenue from backlogged demand. Because the retailer sells out non-detective items at time $M_{i}(i=1,2)$ in this case, there is no interest charged for non-detective items. Therefore, the retailer's opportunity cost per replenishment cycle only includes that for detective items and is given by:

$$
\begin{gathered}
I_{c}\left(1-\delta_{i} \alpha\right) v \lambda Q\left(T-M_{i}\right)=I_{c}\left(1-\delta_{i} \alpha\right) v \\
\lambda D T\left(T-M_{i}\right) /(1-\lambda) .
\end{gathered}
$$

Case 3: $t \leq T \leq M_{i}(i=1,2)$. In this case, as shown in Figure 4, the retailer's interest earned per replenishment cycle is:

$$
\begin{aligned}
& \frac{I_{e} p[(1-\lambda) Q-B] t}{2}+I_{e} p[(1-\lambda) Q-B]\left(M_{i}-t\right) \\
& \quad+I_{e} p B M_{i}+I_{e} k \lambda Q\left(M_{i}-T\right)=I_{e} p D t\left(M_{i}-\frac{t}{2}\right)
\end{aligned}
$$




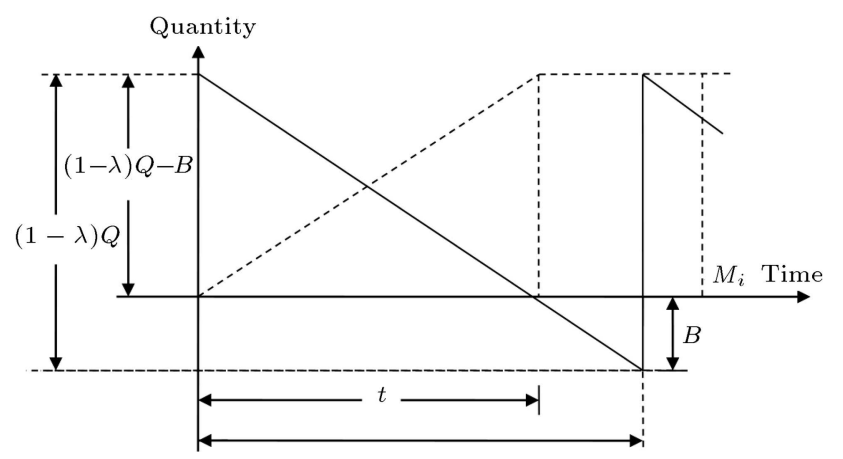

Figure 4. The retailer's inventory system when $t \leq T \leq M_{i}(i=1,2)$.

$$
+I_{e} p D(T-t) M_{i}+I_{e} k \lambda\left(M_{i}-T\right) \frac{D T}{1-\lambda}
$$

where $I_{e} p B M_{i}$ is the interest earned due to the revenue from backlogged demand, and $I_{e} k \lambda Q\left(M_{i}-T\right)$ is the interest earned for sale revenue of detective items. Because the retailer sells out the items (including nondetective and detective items) at time $M_{i}(i=1,2)$, in this case, there is no interest charged.

Consequently, the retailer's total profit per unit time (denoted by $T P R_{i}(T, t)$ ) can be expressed as follows:

$$
T P R_{i}(T, t)=\frac{1}{T}\{\text { gross profit - ordering cost }
$$

- transportation cost - holding cost

- shortage cost - opportunity cost

+ interest earned $\}$

$$
=\left\{\begin{array}{lll}
T P R_{i 1}(T, t), & \text { if } & M_{i} \leq t \leq T, \\
T P R_{i 2}(T, t), & \text { if } & t \leq M_{i} \leq T, \\
T P R_{i 3}(T, t), & \text { if } & t \leq T \leq M_{i},
\end{array}\right.
$$

where $i=1,2$,

$$
\begin{array}{r}
T P R_{i 1}(T, t)=\frac{1}{T}\left\{p D T+\frac{k \lambda D T}{1-\lambda}-\frac{\left(1-\delta_{i} \alpha\right) v D T}{1-\lambda}\right. \\
-A-\left[1-I_{\left[Q_{d}, \infty\right)}(Q)\right](F+r Q)-\frac{h_{b_{1}} D t^{2}}{2} \\
-\frac{h_{b_{2}} \lambda D T^{2}}{1-\lambda}-\frac{\pi D(T-t)^{2}}{2}-\frac{I_{c}\left(1-\delta_{i} \alpha\right) v D\left(t-M_{i}\right)^{2}}{2} \\
-\frac{I_{c}\left(1-\delta_{i} \alpha\right) v \lambda D T\left(T-M_{i}\right)}{1-\lambda}+\frac{I_{e} p D M_{i}^{2}}{2} \\
\left.+I_{e} p D(T-t) M_{i}\right\}=p D+\frac{k \lambda D}{1-\lambda}-\frac{\left(1-\delta_{i} \alpha\right) v D}{1-\lambda}
\end{array}
$$

$$
\begin{aligned}
& -\frac{A}{T}-\left[1-I_{\left[Q_{d}, \infty\right)}(Q)\right]\left(\frac{F}{T}+\frac{r D}{1-\lambda}\right)-\frac{h_{b_{1}} D t^{2}}{2 T} \\
& -\frac{h_{b_{2}} \lambda D T}{1-\lambda}-\frac{\pi D}{2}\left(T-2 t+\frac{t^{2}}{T}\right) \\
& -\frac{I_{c}\left(1-\delta_{i} \alpha\right) v D\left(t-M_{i}\right)^{2}}{2 T} \\
& -\frac{I_{c}\left(1-\delta_{i} \alpha\right) v \lambda D\left(T-M_{i}\right)}{1-\lambda}+\frac{I_{e} p D M_{i}^{2}}{2 T} \\
& +I_{e} p D M_{i}\left(1-\frac{t}{T}\right)
\end{aligned}
$$

$$
\begin{aligned}
& \operatorname{TPR}_{i 2}(T, t)=\frac{1}{T}\left\{p D T+\frac{k \lambda D T}{1-\lambda}\right. \\
& -\frac{\left(1-\delta_{i} \alpha\right) v D T}{1-\lambda}-A-\left[1-I_{\left[Q_{d}, \infty\right)}(Q)\right] \\
& (F+r Q)-\frac{h_{b_{1}} D t^{2}}{2}-\frac{h_{b_{2}} \lambda D T^{2}}{1-\lambda}-\frac{\pi D(T-t)^{2}}{2} \\
& -\frac{I_{c}\left(1-\delta_{i} \alpha\right) v \lambda D T\left(T-M_{i}\right)}{1-\lambda} \\
& \left.+I_{e} p D t\left(M_{i}-\frac{t}{2}\right)+I_{e} p D(T-t) M_{i}\right\} \\
& =p D+\frac{k \lambda D}{1-\lambda}-\frac{\left(1-\delta_{i} \alpha\right) v D}{1-\lambda} \\
& -\frac{A}{T}-\left[1-I_{\left[Q_{d}, \infty\right)}(Q)\right]\left(\frac{F}{T}+\frac{r D}{1-\lambda}\right) \\
& -\frac{h_{b_{1}} D t^{2}}{2 T}-\frac{h_{b_{2}} \lambda D T}{1-\lambda}-\frac{\pi D}{2}\left(T-2 t+\frac{t^{2}}{T}\right) \\
& -\frac{I_{c}\left(1-\delta_{i} \alpha\right) v \lambda D\left(T-M_{i}\right)}{1-\lambda} \\
& +\frac{I_{e} p D t}{T}\left(M_{i}-\frac{t}{2}\right)+I_{e} p D M_{i}\left(1-\frac{t}{T}\right)
\end{aligned}
$$$$
\operatorname{TPR}_{i 3}(T, t)=\frac{1}{T}\left\{p D T+\frac{k \lambda D T}{1-\lambda}\right.
$$$$
-\frac{\left(1-\delta_{i} \alpha\right) v D T}{1-\lambda}-A-\left[1-I_{\left[Q_{d}, \infty\right)}(Q)\right]
$$$$
(F+r Q)-\frac{h_{b_{1}} D t^{2}}{2}-\frac{h_{b_{2}} \lambda D T^{2}}{1-\lambda}
$$$$
-\frac{\pi D(T-t)^{2}}{2} I_{e} p D t\left(M_{i}-\frac{t}{2}\right)
$$ 


$$
\begin{aligned}
& \left.+I_{e} p D M_{i}(T-t)+\frac{I_{e} k \lambda D T\left(M_{i}-T\right)}{1-\lambda}\right\} \\
& =p D+\frac{k \lambda D}{1-\lambda}-\frac{\left(1-\delta_{i} \alpha\right) v D}{1-\lambda} \\
& -\frac{A}{T}-\left[1-I_{\left[Q_{d}, \infty\right)}(Q)\right]\left(\frac{F}{T}+\frac{r D}{1-\lambda}\right) \\
& -\frac{h_{b_{1}} D t^{2}}{2 T}-\frac{h_{b_{2}} \lambda D T}{1-\lambda}-\frac{\pi D}{2}\left(T-2 t+\frac{t^{2}}{T}\right) \\
& +\frac{I_{e} p D t}{T}\left(M_{i}-\frac{t}{2}\right)+I_{e} p D M_{i}\left(1-\frac{t}{T}\right) \\
& +\frac{I_{e} k \lambda D\left(M_{i}-T\right)}{1-\lambda},
\end{aligned}
$$

where $i=1,2$ and $\delta_{1}=1, \delta_{2}=0$.

\subsection{The integrated total profit function}

When the supplier and retailer are treated as an integrated supply chain system and decide to share resources with each other to undertake mutually beneficial cooperation, the joint total profit per unit time can be obtained as the sum of the supplier and retailer's total profit per unit time and is a function of $n, T$ and $t$ as follows:

$$
\begin{aligned}
J T P_{i}(n, T, t)=T P V_{i}(n)+T P R_{i}(T, t) \\
=\left\{\begin{array}{lll}
J T P_{i 1}(n, T, t), & \text { if } & M_{i} \leq t \leq T, \\
J T P_{i 2}(n, T, t), & \text { if } & t \leq M_{i} \leq T, \\
J T P_{i 3}(n, T, t), & \text { if } & t \leq T \leq M_{i},
\end{array}\right.
\end{aligned}
$$

where:

$$
\begin{aligned}
J T & P_{i 1}(n, T, t)=T P V_{i}(n)+T P R_{i 1}(T, t) \\
= & p D+\frac{(k \lambda-c-r) D}{1-\lambda}-\frac{A+F}{T}-\frac{K}{n T} \\
- & \frac{h_{v} D^{2} T}{(1-\lambda)^{2}}\left[\frac{1}{P}+\frac{(n-1)(1-\lambda)}{2 D}-\frac{n}{2 P}\right] \\
- & \frac{I_{v}\left(1-\delta_{i} \alpha\right) v D M_{i}}{1-\lambda} \\
+ & \frac{\delta_{i} I_{p}(1-\alpha) v D\left(M_{2}-M_{1}\right)}{1-\lambda} \\
- & \frac{h_{b_{1}} D t^{2}}{2 T}-\frac{h_{b_{2}} \lambda D T}{1-\lambda}-\frac{\pi D}{2}\left(T-2 t+\frac{t^{2}}{T}\right) \\
- & \frac{I_{c}\left(1-\delta_{i} \alpha\right) v D\left(t-M_{i}\right)^{2}}{2 T}
\end{aligned}
$$

$$
\begin{aligned}
& -\frac{I_{c}\left(1-\delta_{i} \alpha\right) v \lambda D\left(T-M_{i}\right)}{1-\lambda}+\frac{I_{e} p D M_{i}^{2}}{2 T} \\
& +I_{e} p D M_{i}\left(1-\frac{t}{T}\right), \\
J T P_{i 2}(n, T, t)=T P V_{i}(n)+T P R_{i 2}(T, t) & \\
= & p D+\frac{(k \lambda-c-r) D}{1-\lambda}-\frac{A+F}{T}-\frac{K}{n T} \\
- & \frac{h_{v} D^{2} T}{(1-\lambda)^{2}}\left[\frac{1}{P}+\frac{(n-1)(1-\lambda)}{2 D}-\frac{n}{2 P}\right] \\
- & \frac{I_{v}\left(1-\delta_{i} \alpha\right) v D M_{i}}{1-\lambda}+\frac{\delta_{i} I_{p}(1-\alpha) v D\left(M_{2}-M_{1}\right)}{1-\lambda} \\
- & \frac{h_{b_{1}} D t^{2}}{2 T}-\frac{h_{b_{2}} \lambda D T}{1-\lambda}-\frac{\pi D}{2}\left(T-2 t+\frac{t^{2}}{T}\right) \\
- & \frac{I_{c}\left(1-\delta_{i} \alpha\right) v \lambda D\left(T-M_{i}\right)}{1-\lambda} \\
+ & \frac{I_{e} p D t}{T}\left(M_{i}-\frac{t}{2}\right)+I_{e} p D M_{i}\left(1-\frac{t}{T}\right)
\end{aligned}
$$$$
J T P_{i 3}(n, T, t)=T P V_{i}(n)+T P R_{i 3}(T, t)
$$$$
=p D+\frac{(k \lambda-c-r) D}{1-\lambda}-\frac{A+F}{T}-\frac{K}{n T}
$$$$
-\frac{h_{v} D^{2} T}{(1-\lambda)^{2}}\left[\frac{1}{P}+\frac{(n-1)(1-\lambda)}{2 D}-\frac{n}{2 P}\right]
$$$$
-\frac{I_{v}\left(1-\delta_{i} \alpha\right) v D M_{i}}{1-\lambda}
$$$$
+\frac{\delta_{i} I_{p}(1-\alpha) v D\left(M_{2}-M_{1}\right)}{1-\lambda}
$$$$
-\frac{h_{b_{1}} D t^{2}}{2 T}-\frac{h_{b_{2}} \lambda D T}{1-\lambda}-\frac{\pi D}{2}\left(T-2 t+\frac{t^{2}}{T}\right)
$$$$
+\frac{I_{e} p D t}{T}\left(M_{i}-\frac{t}{2}\right)+I_{e} p D M_{i}\left(1-\frac{t}{T}\right)
$$$$
+\frac{I_{e} k \lambda D\left(M_{i}-T\right)}{1-\lambda}
$$$$
i=1,2, \quad \delta_{1}=1, \quad \delta_{2}=0 .
$$

In the following, our purpose here is to determine the optimal replenishment cycle length, $T$, the length of time during which the stock reaches zero, $t$, and the optimal number of shipments per production run from the supplier to the retailer, $n$, which maximizes the joint total profit per unit time, $\operatorname{JTP}_{i}(n, T, t), i=1,2$. 


\section{Solution procedure}

Firstly, for fixed $M_{i}(i=1,2)$ and any given $(T, t)$, we temporarily relax the integer requirement on $n$ and take the second partial derivative of $J T P_{i}(n, T, t)$ with respect to $n$, which gives:

$$
\begin{aligned}
& \frac{\partial^{2} J T P_{i}(n, T, t)}{\partial n^{2}}=\frac{\partial^{2} J T P_{i j}(n, T, t)}{\partial n^{2}}=\frac{-2 K}{n^{3} T}<0, \\
& j=1,2,3 .
\end{aligned}
$$

It is obvious that for any given $(T, t), J T P_{i}(n, T, t)$ is concave function in $n$, where $i=1,2$. Hence, searching for the optimal solution of $n$ is reduced to finding a local optimal solution. Next, for fixed $M_{i}(i=1,2)$ and $n$, we will discuss how to find the optimal solution $(T, t)$. There are three cases arising as follows: (i) $M_{i} \leq t \leq$ $T$, (ii) $t \leq M_{i} \leq T$, and(iii) $t \leq T \leq M_{i}$.

Case 1: $\quad M_{i} \leq t \leq T(i=1,2)$. Taking the first and second partial derivatives of $J T P_{i 1}(n, T, t)$ with respect to $T$ and $t$, respectively, yields:

$$
\begin{gathered}
\frac{\partial J T P_{i 1}(n, T, t)}{\partial T}=\frac{n(A+F)+K}{n T^{2}}-\frac{h_{v} D^{2}}{(1-\lambda)^{2}} \\
{\left[\frac{1}{P}+\frac{(n-1)(1-\lambda)}{2 D}-\frac{n}{2 P}\right]+\frac{\left(h_{b_{1}}+\pi+I_{e} p\right) D t^{2}}{2 T^{2}}} \\
-\frac{\pi D}{2}-\frac{\left[h_{b_{2}}+I_{c}\left(1-\delta_{i} \alpha\right) v\right] \lambda D}{1-\lambda} \\
+\frac{\left[I_{c}\left(1-\delta_{i} \alpha\right) v-I_{e} p\right] D\left(t-M_{i}\right)^{2}}{2 T^{2}}, \\
\frac{\partial^{2} J T P_{i 1}(n, T, t)}{\partial T^{2}}=\frac{-2[n(A+F)+K]}{n T^{3}} \\
-\frac{\left(h_{b_{1}}+\pi+I_{e} p\right) D t^{2}+\left[I_{c}\left(1-\delta_{i} \alpha\right) v-I_{e} p\right] D\left(t-M_{i}\right)^{2}}{T^{3}} \\
\leq \frac{-2[n(A+F)+K]}{n T^{3}} \\
-\frac{\left(h_{b_{1}}+\pi\right) D t^{2}+I_{c}\left(1-\delta_{i} \alpha\right) v D\left(t-M_{i}\right)^{2}}{T^{3}}<0,(12) \\
\frac{\partial J T P_{i 1}(n, T, t)}{\partial t}=-\frac{h_{b_{1}} D t}{T}+\pi D\left(1-\frac{t}{T}\right) \\
\frac{\partial^{2} J T P_{i 1}(n, T, t)}{\partial t^{2}}=-\frac{\left[h_{b_{1}}+\pi+I_{c}\left(1-\delta_{i} \alpha\right) v\right] D}{T}<0, \\
T\left(1-\delta_{i} \alpha\right) v D\left(t-M_{i}\right) \\
T
\end{gathered}
$$

$$
\begin{aligned}
& \frac{\partial^{2} J T P_{i 1}(n, T, t)}{\partial T \partial t}=\frac{\partial^{2} J T P_{i 1}(n, T, t)}{\partial t \partial T} \\
& \quad=\frac{D\left[\left(h_{b_{1}}+\pi\right) t+I_{e} p M_{i}+I_{c}\left(1-\delta_{i} \alpha\right) v\left(t-M_{i}\right)\right]}{T^{2}} .
\end{aligned}
$$

Based on Eqs. (12), (14), and (15), the determinant of Hessian matrix is:

$$
\begin{aligned}
J_{i 1} & =\left|\begin{array}{ll}
\frac{\partial^{2} J T P_{i 1}(n, T, t)}{\partial T^{2}} & \frac{\partial^{2} J T P_{i 1}(n, T, t)}{\partial T \partial t} \\
\frac{\partial^{2} J T P_{1}(n, T, t)}{\partial t \partial T} & \frac{\partial^{2} J T P_{i 1}(n, T, t)}{\partial t^{2}}
\end{array}\right| \\
& =\frac{\partial^{2} J T P_{i 1}(n, T, t)}{\partial T^{2}} \times \frac{\partial^{2} J T P_{i 1}(n, T, t)}{\partial t^{2}} \\
& -\left[\frac{\partial^{2} J T P_{i 1}(n, T, t)}{\partial T \partial t}\right]^{2} \\
& =\frac{2 D[n(A+F)+K]\left[h_{b_{1}}+\pi+I_{c}\left(1-\delta_{i} \alpha\right) v\right]}{n T^{4}} \\
& +\frac{D^{2} M_{i}^{2}\left[I_{c}\left(1-\delta_{i} \alpha\right) v-I_{e} p\right]\left(h_{b_{1}}+\pi+I_{e} p\right)}{T^{4}}
\end{aligned}
$$

where $i=1,2$ and $\delta_{1}=1, \delta_{2}=0$.

Therefore, the following result can be obtained from Eqs. (12), (14), and (16).

Theorem 1. For given $M_{i}(i=1,2)$ and $n$, if $J_{i 1}>$ 0 , then $J T P_{i 1}(n, T, t)$ has a maximum value at point $(T, t)=\left(T_{i 1}, t_{i 1}\right)$ which satisfies $\partial J T P_{i 1}(n, T, t) / \partial T=$ 0 and $\partial J T P_{i 1}(n, T, t) / \partial t=0$.

Case 2: $\quad t \leq M_{i} \leq T(i=1,2)$. Similarly, taking the first and second partial derivatives of $J T P_{i 2}(n, T, t)$ with respect to $T$ and $t$, respectively, yields:

$$
\begin{aligned}
& \frac{\partial J T P_{i 1}(n, T, t)}{\partial T}=\frac{n(A+F)+K}{n T^{2}}-\frac{h_{v} D^{2}}{(1-\lambda)^{2}} \\
& {\left[\frac{1}{P}+\frac{(n-1)(1-\lambda)}{2 D}-\frac{n}{2 P}\right]+\frac{\left.h_{b_{1}}+\pi+I_{e} p\right) D t^{2}}{2 T^{2}}} \\
& -\frac{\pi D}{2}-\frac{\left[h_{b_{2}}+I_{c}\left(1-\delta_{i} \alpha\right) v\right] \lambda D}{1-\lambda},
\end{aligned}
$$

$$
\begin{gathered}
\frac{\partial^{2} J T P_{i 2}(n, T, t)}{\partial T^{2}}=\frac{-2[n(A+F)+K]}{n T^{3}} \\
-\frac{\left(h_{b_{1}}+\pi+I_{e} p\right) D t^{2}}{T^{3}}<0,
\end{gathered}
$$$$
\frac{\partial J T P_{i 2}(n, T, t)}{\partial t}=-\frac{\left(h_{b_{1}}+\pi+I_{e} p\right) D t}{T}+\pi D
$$

$\frac{\partial^{2} J T P_{i 2}(n, T, t)}{\partial t^{2}}=-\frac{\left(h_{b_{1}}+\pi+I_{e} p\right) D}{T}<0$ 


$$
\begin{gathered}
\frac{\partial^{2} J T P_{i 2}(n, T, t)}{\partial T \partial t}=\frac{\partial^{2} J T P_{i 2}(n, T, t)}{\partial t \partial T} \\
=\frac{\left(h_{b_{1}}+\pi+I_{e} p\right) D t}{T^{2}} .
\end{gathered}
$$

Based on Eqs. (18), (20), and (21), the determinant of Hessian matrix is:

$$
\begin{aligned}
J_{i 2} & =\left|\begin{array}{ll}
\frac{\partial^{2} J T P_{i 2}(n, T, t)}{\partial T^{2}} & \frac{\partial^{2} J T P_{i 2}(n, T, t)}{\partial T \partial t} \\
\frac{\partial^{2} J T P_{i 2}(n, T, t)}{\partial t \partial T} & \frac{\partial^{2} J T P_{i 2}(n, T, t)}{\partial t^{2}}
\end{array}\right| \\
& =\frac{\partial^{2} J T P_{i 2}(n, T, t)}{\partial T^{2}} \times \frac{\partial^{2} J T P_{i 2}(n, T, t)}{\partial t^{2}} \\
& -\left[\frac{\partial^{2} J T P_{i 2}(n, T, t)}{\partial T \partial t}\right]^{2} \\
& =\frac{2 D[n(A+F)+K]\left(h_{b_{1}}+\pi+I_{e} p\right)}{n T^{4}}>0,
\end{aligned}
$$

where $i=1,2$ and $\delta_{1}=1, \delta_{2}=0$.

Therefore, the following result can be found from Eqs. (18), (20), and (22).

Theorem 2. For given $M_{i}(i=1,2)$ and $n$, $J T P_{i 2}(n, T, t)$ has a maximum value at point $(T, t)=$ $\left(T_{i 2}, t_{i 2}\right)$ which satisfies $\partial J T P_{i 2}(n, T, t) / \partial T=0$ and $\partial J T P_{i 2}(n, T, t) / \partial t=0$.

Case 3: $t \leq T \leq M_{i}(i=1,2)$. Taking the first and second partial derivatives of $J T P_{i 3}(n, T, t)$ with respect to $T$ and $t$, respectively, yields:

$$
\begin{aligned}
& \frac{\partial J T P_{i 1}(n, T, t)}{\partial T}=\frac{n(A+F)+K}{n T^{2}}-\frac{h_{v} D^{2}}{(1-\lambda)^{2}} \\
& {\left[\frac{1}{P}+\frac{(n-1)(1-\lambda)}{2 D}-\frac{n}{2 P}\right]+\frac{\left.h_{b_{1}}+\pi+I_{e} p\right) D t^{2}}{2 T^{2}}} \\
& -\frac{\pi D}{2}-\frac{\left(h_{b_{2}}+I_{e} k\right) \lambda D}{1-\lambda}
\end{aligned}
$$

$$
\begin{gathered}
\frac{\partial^{2} J T P_{i 3}(n, T, t)}{\partial T^{2}}=\frac{-2[n(A+F)+K]}{n T^{3}} \\
-\frac{\left(h_{b_{1}}+\pi+I_{e} p\right) D t^{2}}{T^{3}}<0,
\end{gathered}
$$$$
\frac{\partial J T P_{i 3}(n, T, t)}{\partial t}=-\frac{\left(h_{b_{1}}+\pi+I_{e} p\right) D t}{T}+\pi D,
$$$$
\frac{\partial^{2} J T P_{i 3}(n, T, t)}{\partial t^{2}}=-\frac{\left(h_{b_{1}}+\pi+I_{e} p\right) D}{T}<0,
$$$$
\frac{\partial^{2} J T P_{i 3}(n, T, t)}{\partial T \partial t}=\frac{\partial^{2} J T P_{i 3}(n, T, t)}{\partial t \partial T}
$$$$
=\frac{\left(h_{b_{1}}+\pi+I_{e} p\right) D t}{T^{2}} .
$$

Based on Eqs. (24), (26), and (27), the determinant of Hessian matrix is:

$$
\begin{aligned}
J_{i 3} & =\left|\begin{array}{ll}
\frac{\partial^{2} J T P_{i 3}(n, T, t)}{\partial T^{2}} & \frac{\partial^{2} J T P_{i 3}(n, T, t)}{\partial T \partial t} \\
\frac{\partial^{2} J T P_{i 3}(n, T, t)}{\partial t \partial T} & \frac{\partial^{2} J T P_{i 3}(n, T, t)}{\partial t^{2}}
\end{array}\right| \\
& =\frac{\partial^{2} J T P_{i 2}(n, T, t)}{\partial T^{2}} \times \frac{\partial^{2} J T P_{i 2}(n, T, t)}{\partial t^{2}} \\
& -\left[\frac{\partial^{2} J T P_{i 2}(n, T, t)}{\partial T \partial t}\right]^{2} \\
& =\frac{2 D[n(A+F)+K]\left(h_{b_{1}}+\pi+I_{e} p\right)}{n T^{4}}>0,
\end{aligned}
$$

where $i=1,2$ and $\delta_{1}=1, \delta_{2}=0$.

Therefore, the following result can be obtained from Eqs. (24), (26), and (28).

Theorem 3. For given $M_{i}(i=1,2)$ and $n$, $J T P_{i 3}(n, T, t)$ has a maximum value at point $(T, t)=$ $\left(T_{i 3}, t_{i 3}\right)$ which satisfies $\partial J T P_{i 3}(n, T, t) / \partial T=0$ and $\partial J T P_{i 3}(n, T, t) / \partial t=0$.

By combining the above-mentioned results, the following algorithm can be developed to find the optimal solution $\left(n^{*}, T^{*}, t^{*}\right)$.

\section{Algorithm}

Step 1. Set $n=1$.

Step 2. For given $n$ and $M_{i}, i=1,2$.

Step 2-1. When $J_{i 1}$ defined in Eq. (16) is greater than zero, find $T_{i 1}$ and $t_{i 1}$ by setting Eqs. (11) and (13) equal to zero and, then, compare them with $M_{i}$, where $i=1,2$. If $M_{i} \leq t_{i 1} \leq T_{i 1}$, then calculate the corresponding joint total profit per unit time $J T P_{1}\left(n, T_{i 1}, t_{i 1}\right)$ from Eq. (7). Otherwise, set $J T P_{1}\left(n, T_{i 1}, t_{i 1}\right)=0$.

Step 2-2. Find $T_{i 2}$ and $t_{i 2}$ by setting Eqs. (17) and (19) equal to zero and, then, compare them with $M_{i}$, where $i=1,2$. If $t_{i 2} \leq M_{i} \leq T_{i 2}$, then calculate the corresponding joint total profit per unit time $J T P_{2}\left(n, T_{i 2}, t_{i 2}\right)$ from Eq. (8). Otherwise, set $J T P_{2}\left(n, T_{i 2}, t_{i 2}\right)=0$.

Step 2-3. Find $T_{i 3}$ and $t_{i 3}$ by setting Eqs. (23) and (25) equal to zero and, then, compare them with $M_{i}$, where $i=1,2$. If $t_{i 3} \leq T_{i 3} \leq M_{i}$, then calculate the corresponding joint total profit per unit time $J T P_{3}\left(n, T_{i 3}, t_{i 3}\right)$ from Eq. (9). Otherwise, set $J T P_{3}\left(n, T_{i 3}, t_{i 3}\right)=0$.

Step 2-4. Find $\max _{i=1,2 ; j=1,2,3} J T P_{j}\left(n, T_{i j}, t_{i j}\right)$ and let:

$$
\operatorname{JTP}\left(n, T_{(n)}, t_{(n)}\right)=\max _{i=1,2 ; j=1,2,3} J T P_{j}\left(n, T_{i j}, t_{i j}\right) .
$$


Step 3. Set $n=n+1$, and repeat Steps 2-1 to 2-4 to get $\operatorname{JTP}\left(n, T_{(n)}, t_{(n)}\right)$.

Step 4. If:

$$
J T P\left(n, T_{(n)}, t_{(n)}\right)<J T P\left(n-1, T_{(n-1)}, t_{(n-1)}\right),
$$

then:

$$
J T P\left(n^{*}, T^{*}, t^{*}\right)=\operatorname{JTP}\left(n-1, T_{(n-1)}, t_{(n-1)}\right) .
$$

Hence:

$$
\left(n^{*}, T^{*}, t^{*}\right)=\left(n-1, T_{(n-1)}, t_{(n-1)}\right),
$$

is the optimal solution. Otherwise, return to Step 3.

\section{Numerical examples}

Example 1. To illustrate the solution procedure, an inventory system with the following data is considered:

- $P=4500$ units/year;

- $D=2000$ units/year;

- $K=\$ 300 /$ setup;

- $A=\$ 50 /$ order;

- $F=\$ 30 /$ shipment;

- $r=\$ 0.01 /$ unit;

- $h_{v}=\$ 1.5 /$ unit $/$ year;

- $h_{b_{1}}=\$ 2 /$ unit/year;

- $h_{b_{2}}=\$ 1.8 /$ unit/year;

- $\pi=\$ 3 /$ unit/year;

- $c=\$ 10 /$ unit;

- $v=\$ 20 /$ unit;

- $p=\$ 40 /$ unit;

- $k=\$ 10 /$ unit;

- $\lambda=0.03$

- $I_{v}=0.05 /$ dollar $/$ year;

- $I_{e}=0.03 /$ dollar $/$ year;

- $I_{c}=0.05 /$ dollar $/$ year;

- $M_{1}=30 / 365$ years;

- $M_{2}=60 / 365$ years;

- $\alpha=0.01$

- $I_{p}=0.03 /$ dollar $/$ year;

- $Q_{d}=500$ units.

By applying the algorithm of Section 4, the solution procedure is shown in Table 2. According to Table 2 , the optimal solution is $\left(n^{*}, T^{*}, t^{*}\right)=$ $(3,0.2119,0.1063)$. Therefore, the retailer's optimal ordering quantity is $Q^{*}=D T^{*} /(1-\lambda)=436.827$ units, the supplier's optimal production quantity is
Table 2. The solution process of Example 1.

\begin{tabular}{ccccc}
\hline $\boldsymbol{n}$ & $\boldsymbol{t}^{*}$ & $\boldsymbol{T}^{*}$ & $\boldsymbol{J T P}\left(\boldsymbol{n}, \boldsymbol{T}^{*}, \boldsymbol{t}^{*}\right)$ & \\
\hline 1 & $t_{11}=0.2133$ & $T_{11}=0.4066$ & 58221.2 \\
2 & $t_{11}=0.1398$ & $T_{11}=0.2713$ & 58390.0 & \\
3 & $t_{11}=0.1063$ & $T_{11}=0.2119$ & 58397.5 & $\leftarrow$ \\
4 & $t_{11}=0.0866$ & $T_{11}=0.1775$ & 58364.0 & \\
\hline
\end{tabular}

Note: " $\longleftarrow$ " denotes the optimal solution of the system.

$n^{*} Q^{*}=1310.48$ units, and optimal joint total profit is $\operatorname{JTP}\left(n^{*}, T^{*}, t^{*}\right)=\$ 58397.5$. In this situation, due to the retailer's optimal quantity $Q^{*}=436.827<Q_{d}=$ 500 , the transportation cost is paid by the retailer. In addition, the retailer's optimal payment policy is to make payments at $M_{1}=30 / 365$ years to enjoy the benefit of cash discount when the supplier provides a two-part trade credit.

Example 2. Using the same data as in Example 1, we study the effects of changes in the retailer's interest earned rate, $I_{e} \in\{0.03,0.04,0.05\}$, and interest charged rate, $I_{c} \in\{0.03,0.04,0.05\}$, on the optimal solutions. The computational results are shown in Table 3. Based on the numerical results of Table 3, the retailer's payment policy is dependent on its interest earned. When the retailer's interest earned rate exceeds a certain threshold (for example, $I_{e}=0.05$ in Table 3), he/she will pay at time $M_{2}$ to enjoy the benefit of permissible delay in payments. Otherwise, the retailer will pay at early time $M_{1}$ to take the price discount instead. Furthermore, to enjoy the benefit of trade credit repeatedly, the retailer may order fewer quantities caused by shorter replenishment cycle as the retailer's interest earned rate, $I_{e}$, increases; hence, the joint total profit increases. On the other hand, the retailer's interest charged rate, $I_{c}$, has a negative impact on the retailer's optimal ordering quantity, supplier's production quantity, and the joint total profit. This is because the retailer may reduce the order quantity to avoid backlog capital when his/her interest charged rate increases. With the fixed numbers of deliveries, the production quantity will reduce. Hence, the decreasing joint total profit will ensue.

Example 3. In order to understand the impacts of the lengths of trade credit $M_{i}$ and discount rate $\alpha$ on optimal solutions, the same data as in Example 1 are used, except $M_{1} \in\{15 / 365,30 / 365,45 / 365\}$, $M_{2} \in\{60 / 365,90 / 365,120 / 365\}$, and $\alpha \in\{0.05$, $0.01,0.015\}$. The computational results are shown in Table 4. According to Table 4, although the effect of the discount rate on the optimal solutions is weak, it has different impacts on the joint total profit in different lengths of trade credit, $M_{1}$. When the length of trade credit of $M_{1}$ is low (for example, $M_{1}=15 / 365$ in Table 4), the joint total profit decreases as the 
Table 3. Optimal solutions for various values of retailer's interest earned and charged.

\begin{tabular}{cccccccc}
\hline $\boldsymbol{I}_{\boldsymbol{c}}$ & $\boldsymbol{I}_{\boldsymbol{e}}$ & $\boldsymbol{t}^{*}$ & $\boldsymbol{T}^{*}$ & $\boldsymbol{n}^{*}$ & $\boldsymbol{Q}^{*}$ & $\boldsymbol{n}^{*} \boldsymbol{Q}^{*}$ & $\boldsymbol{J T P}\left(\boldsymbol{n}^{*}, \boldsymbol{T}^{*}, \boldsymbol{t}^{*}\right)$ \\
\hline \multirow{2}{*}{0.03} & 0.03 & $t_{11}=0.1073$ & $T_{11}=0.2129$ & 3 & 438.891 & 1316.67 & 58400.9 \\
& 0.04 & $t_{11}=0.0995$ & $T_{11}=0.2104$ & 3 & 433.746 & 1301.24 & 58447.3 \\
& 0.05 & $t_{22}=0.0883$ & $T_{22}=0.2059$ & 3 & 424.477 & 1273.43 & 58555.4 \\
& & & & & & & \\
0.04 & 0.03 & $t_{11}=0.1068$ & $T_{11}=0.2124$ & 3 & 437.849 & 1313.55 & 58399.2 \\
& 0.04 & $t_{11}=0.0991$ & $T_{11}=0.2099$ & 3 & 432.819 & 1298.46 & 58445.7 \\
& 0.05 & $t_{22}=0.0883$ & $T_{22}=0.2056$ & 3 & 423.860 & 1271.58 & 58554.9 \\
& 0.03 & $t_{11}=0.1063$ & $T_{11}=0.2119$ & 3 & 436.827 & 1310.48 & 58397.5 \\
& 0.04 & $t_{11}=0.0987$ & $T_{11}=0.2095$ & 3 & 431.908 & 1295.72 & 58444.1 \\
& 0.05 & $t_{22}=0.0883$ & $T_{22}=0.2053$ & 3 & 423.246 & 1269.74 & 58554.4 \\
\hline
\end{tabular}

Table 4. Optimal solutions under various values of $\alpha, M_{1}$ and $M_{2}$.

\begin{tabular}{|c|c|c|c|c|c|c|c|}
\hline$\alpha$ & $M_{2}$ & $M_{1}$ & $t^{*}$ & $T^{*}$ & $Q^{*}$ & $n^{*} Q^{*}$ & $\operatorname{JTP}\left(n^{*}, T^{*}, t^{*}\right)$ \\
\hline \multirow{9}{*}{0.005} & \multirow{3}{*}{$60 / 365$} & $15 / 365$ & $t_{11}=0.115712$ & $T_{11}=0.214772$ & 442.828 & 1328.48 & 58449.5 \\
\hline & & $30 / 365$ & $t_{11}=0.106334$ & $T_{11}=0.211849$ & 436.802 & 1310.41 & 58397.1 \\
\hline & & $45 / 365$ & $t_{12}=0.101317$ & $T_{12}=0.209388$ & 431.728 & 1295.19 & 58361.2 \\
\hline & \multirow{3}{*}{90.365} & $15 / 365$ & $t_{11}=0.115712$ & $T_{11}=0.214772$ & 442.828 & 1328.48 & 58550.7 \\
\hline & & $30 / 365$ & $t_{11}=0.106334$ & $T_{11}=0.211849$ & 436.802 & 1310.41 & 58498.3 \\
\hline & & $45 / 365$ & $t_{12}=0.101317$ & $T_{12}=0.209388$ & 431.728 & 1295.19 & 58462.4 \\
\hline & \multirow{3}{*}{120.365} & $15 / 365$ & $t_{11}=0.115712$ & $T_{11}=0.214772$ & 442.828 & 1328.48 & 58651.9 \\
\hline & & $30 / 365$ & $t_{11}=0.106334$ & $T_{11}=0.211849$ & 436.802 & 1310.41 & 58599.5 \\
\hline & & $45 / 365$ & $t_{12}=0.101317$ & $T_{12}=0.209388$ & 431.728 & 1295.19 & 58563.6 \\
\hline \multirow{9}{*}{0.01} & \multirow{3}{*}{$60 / 365$} & $15 / 365$ & $t_{11}=0.115739$ & $T_{11}=0.214792$ & 442.870 & 1328.61 & 58449.3 \\
\hline & & $30 / 365$ & $t_{11}=0.116346$ & $T_{11}=0.211861$ & 436.827 & 1310.48 & 58397.3 \\
\hline & & $45 / 365$ & $t_{12}=0.101321$ & $T_{12}=0.209396$ & 431.745 & 1295.23 & 58362.3 \\
\hline & \multirow{3}{*}{90.365} & $15 / 365$ & $t_{11}=0.115739$ & $T_{11}=0.214792$ & 442.87 & 1328.61 & 58549.9 \\
\hline & & $30 / 365$ & $t_{11}=0.106346$ & $T_{11}=0.211861$ & 436.827 & 1310.48 & 58498.2 \\
\hline & & $45 / 365$ & $t_{12}=0.101321$ & $T_{12}=0.209396$ & 431.745 & 1295.23 & 58462.9 \\
\hline & \multirow{3}{*}{120.365} & $15 / 365$ & $t_{11}=0.115739$ & $T_{11}=0.214792$ & 442.87 & 1328.61 & 58650.6 \\
\hline & & $30 / 365$ & $t_{11}=0.106346$ & $T_{11}=0.211861$ & 436.827 & 1310.48 & 58598.8 \\
\hline & & $45 / 365$ & $t_{12}=0.101321$ & $T_{12}=0.209396$ & 431.745 & 1295.23 & 58563.6 \\
\hline \multirow{9}{*}{0.015} & \multirow{3}{*}{$60 / 365$} & $15 / 365$ & $t_{11}=0.115767$ & $T_{11}=0.214812$ & 442.912 & 1328.73 & 58449.0 \\
\hline & & $30 / 365$ & $t_{11}=0.106358$ & $T_{11}=0.211874$ & 436.853 & 1310.56 & 58397.9 \\
\hline & & $45 / 365$ & $t_{12}=0.101325$ & $T_{12}=0.209404$ & 431.761 & 1295.28 & 58363.3 \\
\hline & \multirow{3}{*}{90.365} & $15 / 365$ & $t_{11}=0.115767$ & $T_{11}=0.214812$ & 442.912 & 1328.73 & 58549.2 \\
\hline & & $30 / 365$ & $t_{11}=0.106358$ & $T_{11}=0.211874$ & 436.853 & 1310.56 & 58498.0 \\
\hline & & $45 / 365$ & $t_{12}=0.101325$ & $T_{12}=0.209404$ & 431.761 & 1295.28 & 58463.5 \\
\hline & \multirow{3}{*}{120.365} & $15 / 365$ & $t_{11}=0.115767$ & $T_{11}=0.214812$ & 442.912 & 1328.73 & 58649.3 \\
\hline & & $30 / 365$ & $t_{11}=0.106358$ & $T_{11}=0.211874$ & 436.853 & 1310.56 & 58598.2 \\
\hline & & $45 / 365$ & $t_{12}=0.101325$ & $T_{12}=0.209404$ & 431.761 & 1295.28 & 58563.6 \\
\hline
\end{tabular}


discount rate increases. Otherwise, if the length of trade credit of $M_{1}$ is large enough, the joint total profit increases as the discount rate increases. In addition, for the given values of $\alpha$ and $M_{1}$, the length of trade credit of $M_{2}$ has no effect on the retailer and the supplier's optimal ordering and production polices since the optimal retailer's payment policy is payment at time $M_{1}$; however, the joint total profit increases when $M_{2}$ increases, implying an increase in the supplier's interest earned. Finally, for given values of $\alpha$ and $M_{2}$, when the length of trade credit of $M_{1}$ increases, the retailer will pay at time $M_{1}$ to take the price discount and order less quantities to enjoy the benefit of trade credit repeatedly. However, the joint total profit of the supply chain system decreases as $M_{1}$ increases.

Example 4. In this example, we study the effects of changes in other parameters $P, D, K, A, F, r, \pi, h_{v}$, $h_{h_{b_{1}}}, h_{h_{b_{2}}}, C, v, p, k, \lambda, I_{v}, I_{p}$, and $Q_{d}$ on the optimal solutions. The data in this example are identical to those in Example 1. The results of the comparison are shown in Table 5. Based on the results shown in Table 5, the following observations can be made:

(a) When production rate $P$, the holding cost parameters of $h_{v}, h_{b_{1}}, h_{b_{2}}$ or the retailer's wholesale price $v$ increase, all the retailer's length of cycle time, during which the stock reaches zero $t^{*}$, the retailer's length of cycle time $T^{*}$, retailer order quantity $Q^{*}$, supplier production quantity $n^{*} Q^{*}$, and joint total profit $\operatorname{JTP}\left(n^{*}, T^{*}, t^{*}\right)$ decrease;

(b) As for the impact of the value of $D$ or $\lambda$ on the optimal solutions and joint total profit, the values of $t^{*}$ and $T^{*}$ decrease, yet $Q^{*}$ and $n^{*} Q^{*}$ increase when the value of $D$ or $\lambda$ increases. From the economic point of view, the retailer will order more and the supplier will product more in response to increased demand rate or defective rate. While the demand rate has a positive effect, defective rate has a negative effect on the joint total profit;

(c) The value of $K, A$ or $F$ has positive effect on the retailer's and the supplier solutions; however, they have negative effect on the joint total profit of the supply chain system. It is very intuitive of the retailer and supplier to, respectively, order and produce more as the costs such as setup cost, ordering cost, and fixed transportation cost increase. Thus, of course, the joint total profit will reduce;

(d) Although the optimal solutions are not affected by the values of $r, c, k, I_{v}$ or $I_{p}$, the joint total profit increases with a decrease in the values of $r, c$, or $I_{v}$, yet increases in the value of $k$ or $I_{p}$. It is obvious that the retailer's order quantity does not affect the parameters related to the supplier. Further, we find the number of shipments too rigid for changes in the supplier's parameters since the number must be an integer;

(e) As the value of $\pi$ increases, the value of $t^{*}$ increases; however, the values of $T^{*}, Q^{*}, n^{*} Q^{*}$, and $\operatorname{JTP}\left(n^{*}, T^{*}, t^{*}\right)$ decrease. This numerical result is also very intuitive because the retailer will try to avoid stockouts when the shortage cost increases;

(f) The values of $t^{*}, T^{*}, Q^{*}$, and $n^{*} Q^{*}$ decrease, while $\operatorname{JTP}\left(n^{*}, T^{*}, t^{*}\right)$ increases with the increase of the value of $p$, because the retailer may order fewer quantities caused by shorter replenishment cycle as the retailer's selling price increases (implying the interest earned increases) to enjoy the benefit of trade credit repeatedly; hence, the joint total profit increases;

(g) Although the optimal solutions and joint total profit are not affected by the value of $Q_{d}$, it is beneficial for the retailer when the order quantity threshold at which shipping cost is absorbed by the supplier is low (for example, $Q_{d}=400<Q^{*}=$ 436.827 in Table 5).

\section{Conclusion}

Although the inventory-related literatures with trade credit have been widely published, few literatures have considered supply chain inventory model. Moreover, no previous studies have discussed the issue of the freight concession that could effectively promote the order quantity. Therefore, this study investigated an integrated supplier-retailer production and inventory model where the following issues were taken into account simultaneously: (1) The supplier provides a two-part trade credit which allows the retailer to either make full payments at a certain time or pay earlier with a cash discount, (2) The retailer can enjoy a freight concession if the order quantity is over the specified threshold, (3) The retailer's arriving lot contains defective items, and (4) Shortages are allowed for the retailer and completely backlogged. To make the model more rigorous, three theorems were proposed to ensure the existence and uniqueness of the optimal solutions; then, an algorithm was provided to reveal the optimal solutions. Furthermore, numerical examples demonstrating the solution procedures and a sensitivity analysis of the optimal solutions with respect to all parameters were presented. The numerical results yielded several main management insights: (1) When the supplier provides a two-part trade credit, the retailer may order fewer quantities caused by shorter replenishment cycle to enjoy the benefit of trade credit repeatedly. Further, if the retailer's interest earned exceeds a certain threshold (e.g., $I_{e} \geq 0.05$, Example 
Table 5. Optimal solutions under different parametric values.

\begin{tabular}{|c|c|c|c|c|c|c|}
\hline Parameters & Value & $t^{*}$ & $T^{*}$ & $Q^{*}$ & $n^{*} Q^{*}$ & $\operatorname{JTP}\left(n^{*}, T^{*}, t^{*}\right)$ \\
\hline \multirow{3}{*}{$P$} & 4400 & 0.1066 & 0.2123 & 437.741 & 1313.22 & 58400.9 \\
\hline & 4500 & 0.1063 & 0.2119 & 436.827 & 1310.48 & 58397.5 \\
\hline & 4600 & 0.1061 & 0.2114 & 435.958 & 1307.87 & 58394.2 \\
\hline \multirow{3}{*}{$D$} & 1950 & 0.1077 & 0.2142 & 430.554 & 1291.66 & 56912.8 \\
\hline & 2000 & 0.1063 & 0.2119 & 436.827 & 1310.48 & 58397.5 \\
\hline & 2050 & 0.1051 & 0.2096 & 443.055 & 1329.16 & 59882.6 \\
\hline \multirow{3}{*}{$K$} & 275 & 0.1034 & 0.2067 & 426.184 & 1278.55 & 58437.3 \\
\hline & 300 & 0.1063 & 0.2119 & 436.827 & 1310.48 & 58397.5 \\
\hline & 325 & 0.1092 & 0.2169 & 447.203 & 1341.61 & 58358.6 \\
\hline \multirow{3}{*}{$A$} & 45 & 0.1046 & 0.2088 & 430.475 & 1291.42 & 58421.3 \\
\hline & 50 & 0.1063 & 0.2119 & 436.827 & 1310.48 & 58397.5 \\
\hline & 55 & 0.1081 & 0.2149 & 443.084 & 1329.25 & 58374.1 \\
\hline \multirow{3}{*}{$F$} & 25 & 0.1046 & 0.2088 & 430.475 & 1291.42 & 58421.3 \\
\hline & 30 & 0.1063 & 0.2119 & 436.827 & 1310.48 & 58397.5 \\
\hline & 35 & 0.1081 & 0.2149 & 443.084 & 1329.25 & 58374.1 \\
\hline \multirow{3}{*}{$r$} & 0.009 & 0.1063 & 0.2119 & 436.827 & 1310.48 & 58399.6 \\
\hline & 0.01 & 0.1063 & 0.2119 & 436.827 & 1310.48 & 58397.5 \\
\hline & 0.011 & 0.1063 & 0.2119 & 436.827 & 1310.48 & 58395.4 \\
\hline \multirow{3}{*}{$\pi$} & 2.75 & 0.1018 & 0.2132 & 439.522 & 1318.56 & 58411.3 \\
\hline & 3 & 0.1063 & 0.2119 & 436.827 & 1310.48 & 58397.5 \\
\hline & 3.25 & 0.1105 & 0.2107 & 434.417 & 1303.25 & 58385.0 \\
\hline \multirow{3}{*}{$h_{v}$} & 1.4 & 0.1089 & 0.2164 & 446.104 & 1338.31 & 58431.5 \\
\hline & 1.5 & 0.1063 & 0.2119 & 436.827 & 1310.48 & 58397.5 \\
\hline & 1.6 & 0.1039 & 0.2076 & 428.096 & 1284.29 & 58364.2 \\
\hline \multirow{3}{*}{$h_{b 1}$} & 1.95 & 0.1076 & 0.2123 & 437.746 & 1313.24 & 58400.2 \\
\hline & 2 & 0.1063 & 0.2119 & 436.827 & 1310.48 & 58397.5 \\
\hline & 2.05 & 0.1051 & 0.2114 & 435.931 & 1307.79 & 58394.9 \\
\hline \multirow{3}{*}{$h_{b 2}$} & 1.75 & 0.1064 & 0.2119 & 437.002 & 1311.01 & 58398.2 \\
\hline & 1.8 & 0.1063 & 0.2119 & 436.827 & 1310.48 & 58397.5 \\
\hline & 1.85 & 0.1063 & 0.2118 & 436.652 & 1309.96 & 58396.8 \\
\hline \multirow{3}{*}{$c$} & 9.5 & 0.1063 & 0.2119 & 436.827 & 1310.48 & 59428.4 \\
\hline & 10 & 0.1063 & 0.2119 & 436.827 & 1310.48 & 58397.5 \\
\hline & 10.5 & 0.1063 & 0.2119 & 436.827 & 1310.48 & 57366.6 \\
\hline \multirow{3}{*}{$v$} & 18 & 0.1066 & 0.2121 & 437.335 & 1312.01 & 58405.1 \\
\hline & 20 & 0.1063 & 0.2119 & 436.827 & 1310.48 & 58397.5 \\
\hline & 22 & 0.1061 & 0.2116 & 436.324 & 1308.97 & 58389.9 \\
\hline \multirow{3}{*}{$p$} & 38 & 0.1075 & 0.2122 & 437.512 & 1312.53 & 54390.7 \\
\hline & 40 & 0.1063 & 0.2119 & 436.827 & 1310.48 & 58397.5 \\
\hline & 42 & 0.1052 & 0.2115 & 436.129 & 1308.39 & 62404.3 \\
\hline
\end{tabular}


Table 5. Optimal solutions under different parametric values (continued).

\begin{tabular}{ccccccc}
\hline Parameters & Value & $\boldsymbol{t}^{*}$ & $\boldsymbol{T}^{*}$ & $\boldsymbol{Q}^{*}$ & $\boldsymbol{n}^{*} \boldsymbol{Q}^{*}$ & $\boldsymbol{J} \boldsymbol{T} \boldsymbol{P}\left(\boldsymbol{n}^{*}, \boldsymbol{T}^{*}, \boldsymbol{t}^{*}\right)$ \\
\hline \multirow{2}{*}{${ }^{*}$} & 9 & 0.1063 & 0.2119 & 436.827 & 1310.48 & 58335.6 \\
& 10 & 0.1063 & 0.2119 & 436.827 & 1310.48 & 58397.5 \\
$\lambda$ & 0.02 & 0.1076 & 0.2140 & 436.699 & 1310.10 & 58412.8 \\
& 0.03 & 0.1063 & 0.2119 & 436.827 & 1310.48 & 58397.5 \\
& 0.04 & 0.1051 & 0.2098 & 437.006 & 1311.02 & 58382.0 \\
$I_{v}$ & 0.04 & 0.1063 & 0.2119 & 436.827 & 1310.48 & 58431.1 \\
& 0.05 & 0.1063 & 0.2119 & 436.827 & 1310.48 & 58397.5 \\
& 0.06 & 0.1063 & 0.2119 & 436.827 & 1310.48 & 58363.9 \\
$I_{p}$ & 0.02 & 0.1063 & 0.2119 & 436.827 & 1310.48 & 58363.9 \\
& 0.03 & 0.1063 & 0.2119 & 436.827 & 1310.48 & 58397.5 \\
& 0.04 & 0.1063 & 0.2119 & 436.827 & 1310.48 & 58431.1 \\
& & & & & & \\
$Q_{d}$ & 400 & 0.1063 & 0.2119 & 436.827 & 1310.48 & 58397.5 \\
& 500 & 0.1063 & 0.2119 & 436.827 & 1310.48 & 58397.5 \\
& 600 & 0.1063 & 0.2119 & 436.827 & 1310.48 & 58397.5 \\
\hline
\end{tabular}

2 ), the retailer may pay at time $M_{2}$ to benefit from the permissible delay in payments; otherwise, the retailer will pay at early time $M_{1}$ to receive a discount on the purchase price; (2) The retailer will order more and the supplier will produce more in response to increased defective rate of items; however, it has a negative effect on the joint total profit; (3) The number of shipments is rigid for changes in the supplier's parameters since it must be an integer; (4) Although the optimal solutions and joint total profit are not affected by the value of the order quantity threshold in the integrated supply chain, it is an important factor for determining whether the freight should be paid by the retailer or by the supplier.

The proposed model can be extended to include other aspects. For instance, it would be interesting to consider the supply chain system with multiple items or deteriorating items. In addition, inventory shortages are common in business. Some customers willingly wait for backlogged orders during shortage periods, whereas others do not. It is, therefore, necessary to relax the complete restriction on backlogging. Furthermore, the supplier and retailer are not necessarily integrated; the two parties may be only loosely associated or possibly in competition. Future researches should discuss the optimal decisions for the two parties from cooperative and competitive perspectives. On the other hand, staff negligence, aging equipment, ineffective inspection technology, and erroneous inspection results must be considered. Thus, a proportion of non-defective items might be misclassified as defective (termed as a Type I inspection error), and a proportion of defective items might be misclassified as non-defective (termed as
Type II inspection error). Hence, the effects of these inspection errors on any newly proposed model should be considered. Finally, similar to the transportation cost, the number of transportations increases which implies the increasing percentage of carbon emission. Carbon is a basic element in fossil energy, and cutting carbon equals cost savings and operational efficiency. Thus, the effect of carbon emission cost can be taken into account in the future research.

\section{Acknowledgements}

The authors would like to thank the editor and anonymous reviewers for their valuable and constructive comments, which have led to a significant improvement in the manuscript.

\section{References}

1. Emery, G.W. "An optimal financial response to variable demand", J. Financ. Quant. Anal., 22(2), pp. 209-225 (1987).

2. Petersen, M.A. and Rajan, R.G. "Trade credit: theories and evidence", Rev. Financ. Stud., 10(3), pp. 661-691 (1997).

3. Goyal, S.K. "Economic order quantity under conditions of permissible delay in payments", J. Oper. Res. Soc., 36(4), pp. 335-339 (1985).

4. Aggarwal, S.P. and Jaggi, C.K. "Ordering policies of deteriorating items under permissible delay in payments", J. Oper. Res. Soc., 46(1), pp. 658-662 (1995). 
5. Chang, C.T., Ouyang, L.Y., and Teng, J.T. "An EOQ model for deteriorating items under supplier credits linked to ordering quantity", Appl. Math. Model., 27(12), pp. 983-996 (2003).

6. Ouyang, L.Y., Wu, K.S., and Yang, C.T. "A study on an inventory model for non-instantaneous deteriorating items with permissible delay in payments", Comput. Ind. Eng., 51(4), pp. 637-651 (2006).

7. Teng, J.T. "Optimal ordering policies for a retailer who offers distinct trade credits to its good and bad credit customers", Int. J. Prod. Econ., 119(2), pp. 415-423 (2009).

8. Ouyang, L.Y., Teng, J.T., Goyal, S.K., and Yang, C.T. "An economic order quantity model for deteriorating items with partially permissible delay in payments linked to order quantity", Eur. J. Oper. Res., 194(2), pp. 418-431 (2009).

9. Yang, C.T., Pan, Q., Ouyang, L.Y., and Teng, J.T. "Retailer's optimal order and credit policies when a supplier offers either a cash discount or a delay payment linked to order quantity", Eur. J. Oper. Res., 7(3), pp. 370-392 (2011).

10. Sarkar, B., Sana, S.S., and Chaudhuri, K. "An inventory model with finite replenishment rate, trade credit policy and price-discount offer", J. Ind. Eng., 2013, pp. 1-18 (2013).

11. Sarkar, B., Saren, S., and Cárdenas-Barrón, L.E. “An inventory model with trade-credit policy and variable deterioration for fixed lifetime products", Anna. Oper. Res., 229(1), pp. 677-702 (2015a).

12. Lashgari, M., Taleizadeh, A.A., and Sana, S.S. "An inventory control problem for deteriorating items with back-ordering and financial considerations under two levels of trade credit linked to order quantity", J. Ind. Manag. Opt., 12(3), pp. 1091-1119 (2016).

13. Sana, S.S. "An EOQ model with a varying demand followed by advertising expenditure and selling price under permissible delay in payments: for a retailer", Int. J. Modelling, Identification and Control, 5(2), pp. 166-172 (2008).

14. Khanra, S., Ghosh, S.K., and Chaudhuri, K.S. "An EOQ model for a deteriorating item with time dependent quadratic demand under permissible delay in payment", Appl. Math. Comput., 218(1), pp. 1-9 (2011).

15. Sarkar, B. "An EOQ model with delay in payments and time varying deterioration rate", Math. Comput. Model., 55(3-4), pp. 367-377 (2012a).

16. Jaggi, C.K., Kapur, P.K., Goyal, S.K., and Goel, S.K. "Optimal replenishment and credit policy in EOQ model under two-levels of trade credit policy when demand is influenced by credit period", Int. J. Syst. Assur. Eng. Manag., 3(4), pp. 352-359 (2012).

17. Khanra, S., Mandal, B., and Sarkar, B. "An inventory model with time dependent demand and shortages under trade credit policy", Econ. Model., 35, pp. 349355 (2013).
18. Ray, J. "A nonlinear EOQ model with the effect of trade credit", Int. J. Nonlin. Sci. Num., 17(2), pp. 135-144 (2014).

19. Khanra, S., Mandal, B., and Sarkar, B. "A comparative study between inventory followed by shortages and shortages followed by inventory under trade-credit policy", Int. J. Appl. Comput. Math., 1(3), pp. 399-426 (2015).

20. Rosenblatt, M.J. and Lee, H.L. "Economic production cycles with imperfect production processes", IIE Trans., 18(1), pp. 48-55 (1986).

21. Porteus, E.L. "Optimal lot sizing, process quality improvement and setup cost reduction", Oper. Res., 34(1), pp. 137-144 (1986).

22. Lee, H.L. and Rosenblatt, M.J. "Simultaneous determination of production cycles and inspection schedules in a production system", Manag. Sci., 33(9), pp. 11251136 (1987).

23. Lee, H.L. and Rosenblatt, M.J. "A production and maintenance planning model with restoration cost dependent on detection delay", IIE Trans., 21(4), pp. 368-375 (1989).

24. Zhang, X. and Gerchak, Y. "Joint lot sizing and inspection policy in an EOQ model with random yield", IIE Trans., 22(1), pp. 41-47 (1990).

25. Groenevelt, H., Pintelon, L., and Seidmann, A. "Production lot sizing with machine breakdowns", Manag. Sci., 38(1), pp. 104-123 (1992).

26. Kim, C.H. and Hong, Y. "An optimal production run length in deteriorating production processes", Int. J. Prod. Econ., 58(2), pp. 183-189 (1999).

27. Wu, C.C., Chou, C.Y., and Huang, C. "Optimal price, warranty length and production rate for free replacement policy in the static demand market", Omega, 37(1), pp. 29-39 (2009).

28. Tayyab, M., and Sarkar, B. "Optimal batch quantity in a cleaner multi-stage lean production system with random defective rate", J. Cleaner Production, 139, pp. 922-934 (2016).

29. Khan, M., Jaber, M.Y., Guiffrida, A.L., and Zolfaghari, S. "A review of the extensions of a modified EOQ model for imperfect quality items", Int. J. Prod. Res., 132(1), pp. 1-12 (2011).

30. Sarkar, B. "An EOQ model with delay in payments and stock dependent demand in the presence of imperfect production", Appl. Math. Comput., 218(17), pp. 82958308 (2012b).

31. Hsu, J.T. and Hsu, L.F. "An EOQ model with imperfect quality items, inspection errors, shortage backordering, and sales returns", Int. J Prod. Econ., 143(1), pp. 162-170 (2013).

32. Hsu, P.H., Teng, H.M., and Wee, H.M. "Comments on an economic order quantity (EOQ) for items with imperfect quality and inspection errors", Int. J. Ind. Eng. Comput., 4(1), pp. 173-176 (2013). 
33. Yu, H.F. and Lin, S.Y. "An EOQ model for items with acceptable defective part and shortages", J. Ind. Prod. Eng., 30(7), pp. 443-451 (2013).

34. Moussawi-Haidar, L. Salameh, M., and Nasr, W. "Effect of deterioration on the instantaneous replenishment model with imperfect quality items", Appl. Math. Model., 38(24), pp. 5956-5966 (2014).

35. Salameh, M.K. and Jaber, M.Y. "Economic production quantity model for items with imperfect quality", Int. J. Prod. Econ., 64(1-3), pp. 59-64 (2000).

36. Chan, W.M., Ibrahim, R.N., and Lochert, P.B. "A new EPQ model: integrating lower pricing, rework and reject situations", Prod. Plan. Control., 14(7), pp. 588595 (2003).

37. Chiu, Y.P. "Determining the optimal lot size for the finite production model with random defective rate, the rework process, and backlogging", Eng. Optimiz., 35(4), pp. 427-437 (2003).

38. Chiu, S.W. "Optimal replenishment policy for imperfect quality EMQ model with rework and backlogging", Appl. Stoch. Model.Bus., 23(2), pp. 165-178 (2007).

39. Kulkarni, S.S. "Loss-based quality costs and inventory planning: General models and insights", Eur. J. Oper. Res., 188(2), pp. 428-449 (2008).

40. Sarker, B.R., Jamal, A.M.M., and Mondal, S. "Optimal batch sizing in a multi-stage production system with rework consideration", Eur. J. Oper. Res., 184(3), pp. 915-929 (2008).

41. El Saadany, A.M.A. and Jaber, M.Y. "A production/remanufacturing inventory model with price and quality dependent return rate", Comput. Ind. Eng., 58(3), pp. 352-362 (2010).

42. Sana, S.S. "A production-inventory model in an imperfect production process", Eur. J. Oper. Res., 200(2), pp. 451-464 (2010).

43. Sarkar, B., Chaudhuri, K., and Sana, S.S. "A stockdependent inventory model in an imperfect production process", Int. J. Proc. Manage., 3(4), pp. 361-378 (2010).

44. Sarkar, B., Sana, S.S., and Chaudhuri, K. "An imperfect production process for time varying demand with inflation and time value of money-an EMQ model", Expert Syst. Appl., 38(11), pp. 13543-13548 (2011).

45. Sarkar, B. "An inventory model with reliability in an imperfect production process", Appl. Math. Comput., 218(9), pp. 4881-4891 (2012c).

46. Ouyang, L.Y. and Chang, C.T. "Optimal production lot with imperfect production process under permissible delay in payments and complete backlogging", Int. J. Prod. Econ., 144(2), pp. 610-617 (2013).

47. Tsao, Y.C., Chen, T.H., and Huang, S.M. "A production policy considering reworking of imperfect items and trade credit", Flexible Services and Manufacturing Journal, 23(1), pp. 48-63 (2011).
48. Sarkar, B., Gupta, H., Chaudhuri, K., and Goyal, S.K. "An integrated inventory model with variable lead time, defective units and delay in payments", Appl. Math. Comput., 237, pp. 650-658 (2014).

49. Sarkar, B., Cárdenas-Barrón, L.E., Sarkar, M., and Singgih, M.L. "An economic production quantity model with random defective rate, rework process and backorders for a single stage production system", $J$. Manufact. Syst., 33(3), pp. 423-435 (2014).

50. Sarkar, B. and Moon, I. "Improved quality, setup cost reduction, and variable backorder costs in an imperfect production process", Int. J. Product. Econ., 155, pp. 204-213 (2014).

51. Banerjee, A. "A joint economic-lot-size model for purchaser and vendor", Decision. Sci., 17(3), pp. 292311 (1986).

52. Goyal, S.K. "A joint economic-lot-size model for purchaser and vendor: a comment", Decision. Sci., 19(1), pp. 236-241 (1988).

53. Lu, L. "A one-vendor multi-buyer integrated inventory model”, Eur. J. Oper. Res., 81(2), pp. 312-323 (1995).

54. Pal, B., Sana, S.S., and Chaudhuri, K. "Two-echelon competitive integrated supply chain model with price and credit period dependent demand", Int. J. Syst. Sci., 47(5), pp. 995-1007 (2016).

55. Goyal, S.K. "On improving the single-vendor singlebuyer integrated production inventory model with a generalized policy", Eur. J. Oper. Res., 125(2), pp. 429-430 (2000).

56. Yao, M.J. and Chiou, C.C. "On a replenishment coordination model in an integrated supply chain with one vendor and multiple buyers", Eur. J. Oper. Res., 159(2), pp. 406-419 (2004).

57. Chung, C.J. and Wee, H.M. "Optimizing the economic lot size of a three-stage supply chain with backordering derived without derivatives", Eur. J. Oper. Res., 183(2), pp. 933-943 (2007).

58. Chang, H.C., Ho, C.H., Ouyang, L.Y., and Su, C.H. "The optimal pricing and ordering policy for an integrated inventory model when trade credit linked to order quantity", Appl. Math. Model., 33(7), pp. 29782991 (2009).

59. Lin, C.C. and Lin, C.W. "Defective item inventory model with remanufacturing or replenishing in an integrated supply chain", Int. J. Integr. Supply Manag., 6(3-4), pp. 254-269 (2011).

60. Cárdenas-Barróna, L.E., Teng, J.T., Treviño-Garza, G., Wee, H.M., and Lou, K.R. "An improved algorithm and solution on an integrated production-inventory model in a three-layer supply chain", Int. J. Prod. Econ., 36(2), pp. 384-388 (2012).

61. Lin, Y.J., Ouyang, L.Y., and Dang, Y.F. "A joint optimal ordering and delivery policy for an integrated supplier-retailer inventory model with trade credit and defective items", Appl. Math. Comput., 218(14), pp. 7498-7514 (2012). 
62. Su, C.H. "Optimal replenishment policy for an integrated inventory system with defective items and allowable shortage under trade credit", Int. J. Prod. Econ., 139(1), pp. 247-256 (2012).

63. Sana, S.S. "Optimal contract strategies for two stage supply chain”, Econ. Model., 30, pp. 253-260 (2013).

64. Das, B.C., Das, B., and Mondal, S.K. "An integrated inventory model with delay in payment for deteriorating item under Weibull distribution and advertisement cum price-dependent demand", Int. J. Oper. Res., 20(3), pp. 341-368 (2014).

65. Ouyang, L.Y., Chuang, C.J., Ho, C.H., and Wu, C.W. "An integrated inventory model with quality improvement and two-part credit policy", Top, 22(3), pp. 1042-1061 (2014).

66. Giri, B.C., and S. Sharma. "An integrated inventory model for a deteriorating item with allowable shortages and credit linked wholesale price", Optimization Letters, 9(6), pp. 1149-1175 (2015).

67. Ouyang, L.Y., Ho, C.H., Su. C.H., and Yang, C.T. "An integrated inventory model with capacity constraint and order-size dependent trade credit", Comput. Ind. Eng., 84, pp. 133-143 (2015).

68. Sana, S.S. "Optimal production lot size and reorder point of a two-stage supply chain while random demand is sensitive with sales teams' initiatives", Int. J. Syst. Sci., 47(2), pp. 450-465 (2016).

69. Sarkar, B. "Supply chain coordination with variable backorder, inspections, and discount policy for fixed lifetime products", Math. Probl. Eng., 2016, pp. 1-14 (2016).

70. Mahata, P., Mahata, G.C., and De, S.K. "Optimal replenishment and credit policy in supply chain inventory model under two levels of trade credit with timeand credit-sensitive demand involving default risk", $J$. Ind. Eng. Int., pp. 1-12 (2017).

71. Sarkar, B., Saren, S., Sinha, D., and Hur, S. "Effect of unequal lot sizes, variable setup cost, and carbon emission cost in a supply chain model", Math. Probl. Eng., 2015, pp. 1-13 (2015b).

72. Sett, B.K., Sarkar, S., Sarkar, B., and Yun, W.Y. "Optimal replenishment policy with variable deterioration for fixed-lifetime products", Sci. Iran., 23(5), pp. 23182329 (2016).

73. Yang, C.T., Ho, C.H., Lee, H.M., and Ouyang, L.Y. "Supplier-retailer production and inventory models with defective items and inspection erroes in noncooperative and cooperative environments", RAIROOper. Res., In press (2017).

74. Sarkar, B. "A production-inventory model with proba- bilistic deterioration in two-echelon supply chain management", Appl. Math. Model., 37(5), pp. 3138-3151 (2013).

75. Sarkar, B. and Majumder, A. "Integrated vendorbuyer supply chain model with vendor's setup cost reduction", Appl. Math. Comput., 224, pp. 362-371 (2013).

\section{Biographies}

Chih-Te Yang is a Professor in the Department of Industrial Management at Chien Hsin University of Science and Technology in Taiwan. He earned his PhD from the Graduate Institute of Management Sciences at Tamkang University in Taiwan. His research interests are in the field of production/inventory control, and supply chain management. His articles have been published in Omega, International Journal of Production Economics, European Journal of Operational Research, Computers \& Industrial Engineering, International Journal of Systems Science, Applied Mathematics and Computation, International Journal of Production Research, Asia-Pacific Journal of Operational Research, Mathematical Problems in Engineering, TOP, Journal of Scientific \& Industrial Research, RAIRO-Operations Research, Central European Journal of Operations Research and European Journal of Industrial Engineering.

Chien-Hsiu Huang is currently a PhD student in the Department of Management Sciences at Tamkang University in Taiwan. Her research interest is management science and inventory control.

Liang-Yuh Ouyang is a Professor in the Department of Management Sciences at Tamkang University in Taiwan. He earned his MS in Mathematics and $\mathrm{PhD}$ in Management Sciences from Tamkang University. His research interests are in the field of production/inventory control, probability and statistics. He has published in Journal of the Operational Research Society, Computers \& Operations Research, European Journal of Operational Research, Computers and Industrial Engineering, International Journal of Production Economics, IEEE Transactions on Reliability, Production Planning \& Control, TOP, Mathematical and Computer Modelling, Applied Mathematical Modelling, Applied Mathematical and Computation, Journal of Global Optimization, International Journal of Systems Science, European Journal of Industrial Engineering and RAIRO-Operations Research. 